\title{
Effects of mixing two legume species at seedling stage under different environmental conditions
}

\author{
Heba Elsalahy ${ }^{\text {Corresp., } 1,2}$, Sonoko Bellingrath-Kimura ${ }^{1,3}$, Timo Kautz ${ }^{1}$, Thomas Döring ${ }^{4}$ \\ ${ }^{1}$ Albrecht Daniel Thaer-Institute of Agricultural and Horticultural Sciences - Crop Science, Humboldt Universität Berlin, Berlin, Germany \\ 2 Faculty of Science, Botany and Microbiology Department, Assiut University, Assiut, Egypt \\ 3 Research Area "Land Use and Governance”, Leibniz Centre for Agricultural Landscape Research (ZALF), Humboldt Universität Berlin, Müncheberg, \\ Germany \\ ${ }^{4}$ Agroecology and Organic Farming Group, Rheinische Friedrich-Wilhelms Universität Bonn, Bonn, Germany \\ Corresponding Author: Heba Elsalahy \\ Email address: Heba.elsalahy@agrar.hu-berlin.de
}

While intercropping is known to have positive effects on crop productivity, it is unclear whether the effects of mixing species start at the early plant stage, i.e. during germination. We tested whether the germination of two legume species, alsike clover (AC) and black medic (BM), characterized by a contrasting response to water availability and temperature is affected by mixing. We set up four experiments in each of which we compared a 1:1 mixture against the two monocultures, and combined this with various other experimental factors. These additional factors were (i) varied seed densities $(50 \%$, $100 \%$, and $150 \%$ of a reference density) in two field trials in 2016 and 2017, (ii) varied seed densities (high and low) and water availability ( 6 levels, between $25 \%$ and $100 \%$ of water holding capacity, WHC) in a greenhouse pot trial, (iii) varied seed spacing in a climate chamber, and (iv) varied temperatures $\left(12^{\circ} \mathrm{C}, 20^{\circ} \mathrm{C}, 28^{\circ} \mathrm{C}\right)$ and water availability (4 levels between $25 \%$ and $100 \%$ of $\mathrm{WHC}$ ) in a climate chamber. Across all experiments, the absolute mixture effects (AME) on germination ranged between $-9 \%$ and $+11 \%$, with a median of $+1.3 \%$. Within experiments, significant mixture effects were observed, but the direction of these effects was inconsistent. In the field, AME on germination was significantly negative at some of the tested seed densities. A positive AME was observed in the climate chamber at $12^{\circ} \mathrm{C}$, and the mean AME decreased with increasing temperature. Higher density was associated with decreased germination in the field, indicating negative interaction through competition or allelopathy, among seedlings. Our findings indicate that interaction among seeds in species mixtures may be ongoing during germination, but that the direction of the mixture effect is affected by complex interactions with abiotic and biotic factors. 
1 Effects of mixing two legume species at seedling stage under 2 different environmental conditions

3

4

5

6

7

Heba H. Elsalahy ${ }^{1,2, *}$, Sonoko D. Bellingrath-Kimura ${ }^{1,3}$, Timo Kautz ${ }^{1}$, Thomas F. Döring ${ }^{4}$

${ }^{1}$ Albrecht Daniel Thaer-Institute of Agricultural and Horticultural Sciences - Crop Science, Humboldt-University of Berlin, Berlin, Germany

${ }^{2}$ Faculty of Science, Botany and Microbiology Department, Assiut University, Assiut, Egypt

${ }^{3}$ Research Area "Land Use and Governance", Leibniz Centre for Agricultural Landscape Research (ZALF), Humboldt-University of Berlin, Müncheberg, Germany

${ }^{4}$ Agroecology and Organic Farming Group, Rheinische Friedrich-Wilhelms Universität Bonn, Bonn, Germany

Corresponding Author:

Heba Elsalahy ${ }^{1}$

Albrecht-Thaer-Weg 5, 14195 Berlin, Germany

Email address: Heba.elsalahy@agrar.hu-berlin.de

Keywords: agroecosystems, binary mixture, drought, forage legumes, functional traits, germination, monoculture

\section{ABSTRACT}

While intercropping is known to have positive effects on crop productivity, it is unclear whether the effects of mixing species start at the early plant stage, i.e. during germination. We tested whether the germination of two legume species, alsike clover (AC) and black medic (BM), characterized by a contrasting response to water availability and temperature is affected by mixing. We set up four experiments in each of which we compared a 1:1 mixture against the two monocultures, and combined this with various other experimental factors. These additional factors were (i) varied seed densities $(50 \%, 100 \%$, and $150 \%$ of a reference density) in two field trials in 2016 and 2017, (ii) varied seed densities (high and low) and water availability (6 levels, between $25 \%$ and $100 \%$ of water holding capacity, WHC) in a greenhouse pot trial, (iii) varied seed spacing in a climate chamber, and (iv) varied temperatures $\left(12^{\circ} \mathrm{C}, 20^{\circ} \mathrm{C}, 28^{\circ} \mathrm{C}\right)$ and water availability ( 4 levels between $25 \%$ and $100 \%$ of WHC) in a climate chamber. Across all experiments, the absolute mixture effects (AME) on germination ranged between $-9 \%$ and $+11 \%$, with a median of $+1.3 \%$. Within experiments, significant mixture effects were observed, but the direction of these effects was inconsistent. In the field, AME on germination was significantly negative at some of the tested seed densities. A positive AME was observed in the climate chamber at $12^{\circ} \mathrm{C}$, and the mean AME decreased with increasing temperature. Higher density was associated with decreased germination in the field, indicating negative interaction through 
40 competition or allelopathy, among seedlings. Our findings indicate that interaction among seeds

41 in species mixtures may be ongoing during germination, but that the direction of the mixture

42 effect is affected by complex interactions with abiotic and biotic factors.

43

44

45

46

47

48

49

50

51

52

53

54

55

56

57

58

59

60

61

62

63

64

65

66

67

68

69

70

71

72

73

74

75

76

77

78

79

\section{INTRODUCTION}

Diverse cover crop species are used in agriculture during fallow periods to provide various ecosystem services, such as increasing soil fertility for the next crop, nutrient recycling, suppressing weeds, and protecting soils against erosion (Döring et al., 2013; Elsalahy et al., 2019). Using these species in mixtures can increase the benefits that are conferred by the cover crops (Döring et al., 2013; Stagnari et al., 2017; Storkey et al., 2015). Further, many cover crops are great forage crops, and using them in binary mixtures demonstrated high yield and nutritive value of the selected species (Aponte, Samarappuli \& Berti, 2019; Bélanger et al., 2017; Cherney et al., 2020; Waldron et al., 2020). Thereby, cover crop mixtures may constitute a promising future for sustainable agricultural systems and forage production.

One challenge is to successfully establish cover crop stands in a competitive environment, e.g., when the temperature is too low or too high and the amount of precipitation is too low for optimum growth conditions. In particular depending on sowing date, environmental conditions may vary strongly during early plant development. Studies on cover crop mixtures demonstrated. Studies on cover crop mixtures demonstrated that mixing species with asynchronous growth, i.e., the dominance of different species at different points in time may provide positive mixture effects on the expected services in unpredictable conditions (Elsalahy et al., 2020; Mori et al., 2013). This approach may reduce species competitiveness under conditions of limited growth and allow for complementary crop growth (Elsalahy et al., 2020).

However, in cropping systems, it has not been demonstrated yet whether there are mixture effects on seed germination and seedling emergence, i.e. at the very beginning of plant interactions. This is important since it is known that the ability of a species to germinate faster than its neighbours may affect species performance and dominance in the mixture (Goldberg \& Landa, 1991; Fenesi et al., 2020; Tielbörger \& Prasse, 2009; Verdú \& Traveset, 2005). A simple example of making use of mixture effects in the context of germination is risk reduction; plants vary in temperature and water requirements for germination, hence choosing species with contrasting germination abilities and requirements would decrease the risk of non-emergence in unpredictable environments (Tribouillois et al., 2016). Understanding the different aspects of seed germination in mixtures under different environmental conditions may thus help to secure successful crop establishment and to promote positive mixture effects.

Temperature and water availability are particularly important factors that regulate germination (Hatfield \& Prueger, 2015; Luo et al., 2018; Tribouillois et al., 2016). In addition to the environmental quality, the biotic environment, in particular, the density and identity of neighboring seeds or seedlings may affect the behavior of seed germination in the mixture (Goldberg \& Landa, 1991; Tielbörger \& Prasse, 2009; Leverett, Schieder \& Donohue, 2018). Plants use a number of cues allowing them to assess the best time for germination in intra- and 
80

81

82

83

84

85

86

87

88

89

90

91

92

93

94

95

96

97

98

99

100

101

102

103

104

105

106

107

108

109

110

111

112

113

114

115

116

117

118

interspecific competition, e.g. the moisture content, proper temperature, the density of the neighbour seeds (Bergelson \& Perry, 1989; Tielbörger \& Prasse, 2009). An important component of this plasticity is accelerated seedling emergence in competitive neighborhoods (Sales et al., 2013; Tielbörger \& Prasse, 2009; Verdú \& Traveset, 2005). The potential mechanisms of seed germination plastically responding to neighbors may be attributed to the fact that germinating seeds may emit volatile organic compounds (VOCs) based on the growing conditions (Fincheira, Parada \& Quiroz, 2017; Motsa et al., 2017). Studies showed that temperature level affects production rates of VOCs and may change the volatile composition via affecting enzyme activity that degrades the storage reserves in the seeds; hence affects breaking seed dormancy (Effah, Holopainen \& McCormick, 2019; Motsa et al., 2017). It is therefore likely that environmental conditions may have an effect on the interactions among seeds, and thereby on potential mixture effects.

We, therefore, tested whether or not the germination of the only-legume mixture is affected by the identity of neighboring seeds or seedlings under different temperature and moisture conditions. In particular, we studied the mixture effect on germination for two perennial forage legume species that have different responses to water and temperature requirements. We chose alsike clover (AC; Trifolium hybridum L.) and black medic (BM; Medicago lupulina L.) and a 1:1 mixture of the two species as previous studies showed a positive mixture effect of these two species at this proportion regarding productivity, weed suppression, and resilience to drought (Elsalahy et al., 2019; Elsalahy et al., 2020). BM is a fast-growing perennial well adapted to warm and dry areas (Döring et al., 2013; Elsalahy et al., 2019; FAO, 2020; Komainda et al., 2019 ) with a base temperature of $0.6^{\circ} \mathrm{C}$ and optimal germination temperature of $26^{\circ} \mathrm{C}$ (Tribouillois et al., 2016). Nonetheless, it was also reported for BM that the optimal range of temperatures lies between $10^{\circ} \mathrm{C}$ and $20^{\circ} \mathrm{C}$ (Sharpe \& Boyd, 2019). Conversely, AC is a more slowly growing and comparatively drought-sensitive perennial (Chapman et al., 1990), with less tolerance to drought or high temperature (Sheaffer et al., 2003), and best adapted to cool and wet areas (Döring et al., 2013; Nation, 1989). The minimal germination temperature of AC has been given as $2^{\circ} \mathrm{C}\left(\right.$ Kahnt, 2008) or $5^{\circ} \mathrm{C}$ (Hartmann \& Lunenberg, 2013). In addition, both of the species are classified as cool-season legumes, namely, they are characterized by decreasing germination rate at temperatures greater than the optimal temperature range (Butler et al., 2014).

We hypothesized that germination would be higher in the mixture than in the respective monocultures. This was mainly based on the assumption of relaxed competitive pressure on germinating plants. However, in a complex system, e.g., in the field, the competition between the germinated seeds and germinated weeds, at the early stage, may interact with environmental conditions, and drive mixture effect in a specific direction. To test our hypothesis, we used a set of experiments to observe the germination of the monocultures and the mixture at different seed densities, drought intensities, temperature levels, and seed spacing. Field trials over two years were used to represent the most complex environment, whereas pot and laboratory trials were designed to limit specific sources of variation. This range of different trials allowed us to test our 
119

120

121

122

123

124

125

126

127

128

129

130

131

132

133

134

135

136

137

138

139

140

141

142

143

144

145

146

147

148

149

150

151

152

153

154

155

156

157

158

central hypothesis under different environmental conditions, and varied environmental complexity, which ranged from low, as in the climate chambers, to high, as in the field.

\section{MATERIALS \& METHODS}

\section{General set-up}

Two field trials, a one-pot trial, and two laboratory trials were performed to study potential mixture effects on germination of two legume species AC (cv. Dawn) and BM (cv. Ekola), and an equiproportional (1:1) substitutive mixture of the two species. The seeds of AC and BM were bought from Deutsche Saatveredelung AG (DSV) and Camena Samen, Germany, respectively. For all trials, seeds were left unsterilized before sowing to mimic common agricultural practice. In the field, the seed placement of the two species, in the mixture, was spatially random based on the mechanical distribution of the seeds in the rows of each plot. In contrast, in the pot and laboratory trials, the seeds of the two species, in the mixture, were precisely spatially alternated to ensure maximal interspecific interaction..

\section{Field trials}

To measure potential mixture effects of germination and seedling emergence under field conditions, two field trials were conducted in 2016 (field FU9) and 2017 (field S5), respectively. Both trials were conducted at the experimental field station of the Humboldt University of Berlin in Dahlem $\left(52^{\circ} 28^{\prime} \mathrm{N}, 13^{\circ} 18^{\prime} \mathrm{E}, 51 \mathrm{~m}\right.$ asl). In both fields, soil fertility and soil type varied strongly, specifically sandy clay loam and sandy loam were in field FU9 and field S5, respectively (Elsalahy et al., 2019). The crop sequence in both field trials was cereals - potatowinter wheat-legumes.

The experimental design in both years was a randomized complete block design with 3 replicates in 2016 and 4 replicates in 2017, as previously described in Elsalahy et al., 2019, with the factor diversity (called $D I V$ ) comprising 3 diversity treatments (two monocultures and one mixture) and three different sowing densities (called Den) representing 50\%, 100\%, and 150\% of typically recommended seed density (i.e. the reference density). The number of blocks increased to 4 in 2017 to increase the precision of the findings from the year 2016. Seeding rates were 7.6 and $17.6 \mathrm{~kg} \mathrm{ha}^{-1}$ of $\mathrm{AC}$ and $\mathrm{BM}$, respectively, and their thousand-grain weight was $0.80 \mathrm{~g}$ for AC and $1.85 \mathrm{~g}$ for BM (Elsalahy et al., 2019). The absolute number of seeds in the monocultures at $150 \%$ seed density was approx. 1600 seed $\mathrm{m}^{-2}$. The seeds were weighed and mixed thoroughly in case of the mixture and kept at room temperature (approximately $20{ }^{\circ} \mathrm{C}$ ) for a few days before sowing. Sowing time was on $29^{\text {th }}$ and $25^{\text {th }}$ April in 2016 and 2017, respectively. Sowing depth was $0.5 \mathrm{~cm}$ and was adjusted precisely in the field by using a sowing machine (Wintersteiger AG, Ried im Innkreis, Austria). Plot size was $3 \mathrm{~m}$ x $9 \mathrm{~m}$ including plot margins. Each plot consisted of 20 rows with $13.5 \mathrm{~cm}$ spacing between rows.

Counting of emerged seedlings was performed in a number of selected $0.5 \mathrm{~m}$ long sections from the middle of the plots, i.e. counting was only done within the central $7 \mathrm{~m}$ of the total $9 \mathrm{~m}$ plot length, and omitting the outer rows, thereby avoiding potential edge effects (Fig. S1). The 
159

160

161

162

163

164

165

166

167

168

169

170

171

172

173

174

175

176

177

178

179

180

181

182

183

184

185

186

187

188

189

190

191

192

193

194

195

196

197

198

total number of samples per each of the 9 variants $(3 D I V \times 3 D e n)$ was $\mathrm{n}=24(8$ sections $\times 3$ blocks) in 2016 and $n=48$ (12 sections $x 4$ blocks) in 2017. The time of counting was based on calculating the growing degree days (GDD; ${ }^{\circ} \mathrm{Cd}$ ) of BM by using a base temperature of $0.6{ }^{\circ} \mathrm{C}$ (Tribouillois et al., 2016) to compare plants in similar growth stages across experimental years. Depending on these calculations the plants were specifically counted at $390{ }^{\circ} \mathrm{Cd}$ (25 days after sowing; DAS) and $381^{\circ} \mathrm{Cd}(28 \mathrm{DAS})$ in 2016 and 2017, respectively. The plants in the counting areas were manually separated into three fractions of $\mathrm{AC}, \mathrm{BM}$, and all other species which were considered as weeds.

\section{Pot trial}

The trial was started on $1^{\text {st }}$ June 2016. The greenhouse conditions, the experimental design, and the irrigation strategy of the pot experiment were previously described in Elsalahy et al., 2020. Specifically, the greenhouse was protected on all sides with a wire mesh woven in a plain weave pattern (1" x 1" clear opening, 0.125" Dia. Wire). The size of the openings (spaces) of the wire mesh allowed insects, the wind, and temperature to be in the greenhouse as natural as in the field but prevented any animals such mice from entering. The roof of the greenhouse was covered with polycarbonate plastic panels (16 mm triple wall) that allowed $76 \%$ light transmission. The average daily temperature during the considered period for germination was $19.2^{\circ} \mathrm{C}$, ranging from $10.4^{\circ} \mathrm{C}$ to $28.3^{\circ} \mathrm{C}$ (Agricultural Climatology of the HU-Berlin, 2019).

The experimental design was a three-factorial randomized complete block design in 4 replicates with the factor diversity ( $D I V ; 3$ diversity treatments), the density factor (called Den) with low and high seed densities, and the drought factor (called $C D$ ), with 6 levels of cumulative drought intensity $(100 \%, 85 \%, 70 \%, 55 \%, 40 \%$ and $25 \%$ of WHC). Each block contained 18 pots and one control pot without plants was used to calculate the daily evaporated water. The soil was taken from the top-soil (upper $\sim 15 \mathrm{~cm}$ ) of a non-cropped bare field (field FU9) at the experimental station of the Humboldt University of Berlin in Dahlem. The soil was a sandy clay loam (Brady \& Weil, 2002), had a pH of 6.3, organic matter content of $1.24 \%$, N content of $0.13 \%$, and nutrient contents per $\mathrm{kg}$ soil of $251 \mathrm{mg} \mathrm{P}, 90 \mathrm{mg} \mathrm{K}, 52 \mathrm{mg} \mathrm{Mg}, 1471 \mathrm{mg} \mathrm{Ca}$, and $7354 \mathrm{mg} \mathrm{Fe}^{3+}$. Soil WHC was measured in 3 replicates and calculated following (Nguyen \& Lehmann, 2009).

One day before sowing, square pots $(12 \mathrm{~cm}$ x $12 \mathrm{~cm}$ x $19 \mathrm{~cm}$ height) were filled with $3430 \mathrm{~g}$ of the soil. Then, on the day of sowing, $478 \mathrm{ml}$ distilled were added to each pot to moisten the soil and to facilitate placing the seeds in fixed distances without silting up the soil surface. Seeds were sown at a depth of $0.5 \mathrm{~cm}$. A handmade wooden seed stamp was used to adjust the space between sown seeds in a design of $3 \times 4$ ( $4 \mathrm{~cm}$ space, 12 seeds pot $\left.{ }^{-1}\right)$ and $6 \times 4$ ( $2 \mathrm{~cm} \mathrm{space;} 24$ seeds pot $^{-1}$ ) at low and high seed densities, respectively. These densities were roughly equivalent to seed densities at $77.5 \%$ and $155 \%$ of the reference density in the field. Three days later, an equal amount of water was added to all treatments to compensate for evaporation and ensure optimum conditions for germination in all treatments by keeping WHC at $\sim 90 \%$ before starting the different irrigation regimes. 
199

200

201

202

203

204

205

206

207

208

209

210

211

212

213

214

215

216

217

218

219

220

221

222

223

224

225

226

227

228

229

230

231

232

233

234

235

236

237

238

In the second week after sowing, differentiated irrigation was initiated, creating six different levels. Precise irrigation was facilitated by using a dispenser (Rotilabo ${ }^{\circledR}$-Dispenser 20-100 ml, accuracy $1 \mathrm{ml}$, by Roth, Germany). The average weight of the control pots (without plants) was determined to represent the amount of evaporated water. This amount was then given to the $100 \%$ WHC level and reduced proportionally based on the level of drought intensities (Fig. 1A). Germinated seeds were counted fifteen days after sowing. Any emerged weed seedlings were removed daily from the pots.

\section{Laboratory trial 1}

This trial tested the effects of two factors, species mixing (DIV) and seed spacing (called SPA) in a factorial set up. As in the other trials, the factor $D I V$ contained three levels (AC, BM, and a 1:1 mixture of both species). The factor seed spacing had two levels, called 'single' and 'double' seeds. In the single seed treatment, single seeds were equally spaced with a $1 \mathrm{~cm}$ distance between seeds. In the double seed treatment, seeds were sown in pairs, i.e. as closely together as possible ( $\sim 1 \mathrm{~mm}$ distance); depending on the level of the mixture treatment these pairs of seeds either contained two seeds of the same species or two seeds of different species. Pairs were spaced $2 \mathrm{~cm}$ apart, so that the overall seed density was the same for the two spacing treatments. The trial was set up in a randomized block design with 12 replications.

Seeds were sown in shallow plastic trays $(50 \times 30 \mathrm{~cm})$, by manually placing them onto a layer of $2 \mathrm{~cm}$ deep sieved standard growing substrate ('Terrasoil', DIN 18035 part 4 and RAL GZ 515/2, Cordel-Bau GmbH, Wallenborn, Germany), and covering them with $1 \mathrm{~cm}$ of the same substrate. This resulted in a total volume of $4.5 \mathrm{~L}$ substrate per tray. Each tray constituted one block; 18 seeds were sown per treatment per block, resulting in a total of $12 \times 18=216$ seeds per treatment. Directly after sowing, each tray was carefully irrigated with $350 \mathrm{ml}$ tap water. Trays were then kept in a climate chamber with a constant temperature at $20^{\circ} \mathrm{C}$ and a light regime of $12 / 12 \mathrm{~h}$. Every day each tray was watered with $275 \mathrm{ml}$. Germination was evaluated daily, but here we only present the final germination rate, as the percentage of developed viable seedlings two weeks after sowing.

\section{Laboratory trial 2}

The experiment was conducted in growth chambers (RuMed Rubarth Apparate GmbH, Typ 3501 , Germany) under precise control of temperature levels and dark conditions. The experimental design of the germination experiment was a three-factorial randomized complete block design in 4 replicates. The experimental factors comprised the factor diversity ( $D I V ; 3$ levels: $\mathrm{AC}, \mathrm{BM}$, and the mixture, as above), the drought factor (called $C D$ ), with 4 levels of drought intensity $(100 \%, 75 \%, 50 \%$, and $25 \% \mathrm{WHC})$, and temperature factor (Called $T)$, with three levels of $12^{\circ} \mathrm{C}, 20^{\circ} \mathrm{C}$, and $28^{\circ} \mathrm{C}$. Thus, each block contained 36 treatments. The soil was collected from the same area used for the pot trial, sieved through a sieve $5 \mathrm{~mm}$ mesh size, dried, and sterilized in the oven (Thermo Scientific Heraeus UT 6760, Germany) at $105^{\circ} \mathrm{C}$ for $48 \mathrm{~h}$.

Rectangular plastic boxes with a volume of $750 \mathrm{~cm}^{3}(15 \mathrm{~cm}$ length $\mathrm{x} 10 \mathrm{~cm}$ width $\mathrm{x} \mathrm{cm}$ height) were filled with $100 \mathrm{~g}$ of the sterilized soil, which was moistened with the calculated 
239 WHC of the sterilized dry soil. The amount of water required to initiate the drought intensities 240 was added once by using distilled water at $43.3,32.5,21.6$, and $10.8 \mathrm{ml} \mathrm{box}^{-1}$ for the levels $241100 \%, 75 \%, 50 \%$, and $25 \%$ of WHC, respectively. The seed density was 24 seeds box ${ }^{-1}$ which

242 was equivalent to the $150 \%$ seed density in the field (see above). The seeds were placed on the 243 surface of the moistened soil and placed in dark incubators under controlled temperatures. The 244 distances between the seeds were fixed by using a handmade seed stamp of 100 microns thick

245

246

247

248

249

250

251

252

253

254

255

256

257

258

259

260

261

262

263

264

265

266

267

268

269

270

271

272

273

274

275 transparent sheet (DATALINE transparency film, EU) with an area of $15 \mathrm{~cm} \mathrm{x} 10 \mathrm{~cm}$. The stamp was pierced in a design of $6 \times 4$ to have a $2 \mathrm{~cm}$ space between the seeds. The boxes were covered with their transparent plastic covers to prevent moisture loss and were then randomized within the shelves in the growth chamber.

The temperature levels were constant during the experimental period as studies on BM reported no significant difference in its germination percentage at constant vs. fluctuating temperatures (Sharpe \& Boyd, 2019; Tribouillois et al., 2016). Based on calculating the growing degree days (GDD; ${ }^{\circ} \mathrm{Cd}$ ) of $\mathrm{BM}$ of $0.6^{\circ} \mathrm{Cd}$ (Tribouillois et al., 2016) for the 5 experimental days, the seeds were counted after accumulating 68,185 and $349^{\circ} \mathrm{Cd}$ at temperatures $12^{\circ} \mathrm{C}$, $20^{\circ} \mathrm{C}$, and $28^{\circ} \mathrm{C}$ respectively.

The trial was replicated three times with renewing the sterilized soil and interchanging the temperature levels between the growth chambers to avoid potential incubator effects.

Germination assessment was done by counting the germinated seeds once after 5 days of sowing. A seed was considered to have germinated when its radicle had been pushed out with a length of $\geq 0.2 \mathrm{~cm}$.

\section{Calculation of indices}

The effect of mixing seeds on germination was estimated at the different climate conditions by considering the absolute mixture effect (AME), i.e. the difference between the counted seeds in the mixture and the average counted seeds of the two monocultures (Elsalahy et al., 2019;

Elsalahy et al., 2020) as in Eq. (1).

$$
\mathrm{AME}=y_{\text {mix }}-\left(y_{A C}+y_{B M}\right) / 2
$$

In analogy to the frequently used Land Equivalent Ratio (LER) and partial LER that were calculated in Elsalahy et al., 2020, the germination ratio (GR) and the partial germination ratios (pGR) of each species were calculated, in order to quantify the contribution and dominance of each species in the mixture in Eq. (2).

$$
\mathrm{GR}=\mathrm{PGR}_{\mathrm{AC}}+\mathrm{PGR}_{\mathrm{BM}}=\frac{\mathrm{g}_{\mathrm{AC} \_ \text {mix }}}{\mathrm{g}_{\mathrm{AC} \_ \text {mono }}}+\frac{\mathrm{g}_{\mathrm{BM} \_ \text {mix }}}{\mathrm{g}_{\mathrm{BM} \_ \text {mono }}}
$$

where $\mathrm{g}_{\mathrm{AC} \_ \text {mono }}$ and $\mathrm{g}_{\mathrm{BM} \_ \text {mono }}$ are the germinated seeds of species $\mathrm{AC}$ and $\mathrm{BM}$ in monoculture and $\mathrm{g}_{\mathrm{AC} \_ \text {mix }}$ and $\mathrm{g}_{\mathrm{BM} \_ \text {mix }}$ are the germinated seeds of each species in the mixture. A GR $>1$ indicates that the mixture is more efficient in terms of germination than the monocultures. Partial GRs can be interpreted as a measure for the contribution of each species according to its density ratio in the mixture relative to the monoculture. 
276

277

278

279

280

281

282

283

284

285

286

287

288

289

290

291

292

293

294

295

296

297

298

299

300

301

302

303

304

305

306

307

308

309

310

311

312

313

314

315

A nonlinear mixed-effects regression model with two parameters (Weibull function) was used to estimate the germination percentage of $\mathrm{AC}$ and $\mathrm{BM}$ in monocultures and mixtures at the different temperature levels as a function of water availability WHC using Eq. (3).

$$
y=a *(1-\exp (b * x))
$$

where $y$ is germination percentage, $x$ is the WHC level, and $a$ and $b$ are estimated parameters, with $a$ being the upper asymptote, i.e. representing the final germination percentage.

\section{Statistical analysis}

The steps of the statistical analysis, the selected models, and using some specific tests for distinct response variables were previously described in Elsalahy et al., 2020. Specifically, a generalized linear model (GLM) with binomial error distribution and a probit link function was used to analyze germination in all trials. In the field, pot, laboratory 2 trials, as a first step a full model was used with considering the main factors and all possible interactions as fixed effects.

Subsequently, to simplify interpreting the results, further submodels were used by considering two main factors and the interaction between them. In these trials, block effect was removed from the model as it did not improve the model according to Akaike's information criterion (AIC) (Burnham et al., 2011). In the full model and each sub-model, the normality of residuals was checked by using Shapiro test.

In the two field trials, the full model was constrained to DIV, Den, Year, and all possible interactions. Then, to evaluate the germination of the plants in the monocultures and the mixture at different seed densities in response to different environmental conditions, the submodels included DIV, Den, and DIV $\times$ Den. In the pot trial, the full model was constrained to DIV, $C D$, $D e n$, and all possible interactions. Subsequently, to evaluate plant response to water availability at different seed densities, the submodels were limited to $D I V, C D$, and $D I V \times C D$. In laboratory trial 2, the full model was constrained to $D I V, C D, T$, and all possible interactions. Subsequently, to evaluate plant response to water availability at different temperatures, the submodels constrained $D I V, C D$, and $D I V \times C D$. However, in laboratory trial 1, only a full model was used that constrained $D I V, S P A$, and $D I V \times S P A$.

In the laboratory trial 2, to plot the germination response curves at the different temperatures, an extended non-linear regression model (with lower limit at 0 and upper limit estimated at 100) was fitted as described in Eq. (3). As the variance was not homogenous in this case, the correlation $=$ corAR 1 function was added to the model using the nlme package (Pinheiro et al., 2018). Goodness-of-fit between predicted and observed data was assessed by means of the coefficient of determination $\left(\mathrm{R}^{2}\right)$.

The significance of AME was determined, after ANOVA, by Tukey's HSD test $(\alpha=0.05)$ by using the Agricola R-package (De Mendiburu, 2019). Specifically, in the field trials, AME was compared at different seed densities (Den) in each year, in the pot trial, at different drought intensities $(C D)$, in laboratory trial 1, at different seed spacing $(S P A)$, and in laboratory trial 2 , at different temperatures $(T)$. In all trials, the significance of GR being $\neq 1$ was tested by using twosided Welch's t-tests against 1. All statistics were performed using $\mathrm{R}$ (version 3.6.1) with $\mathrm{R}$ studio (version 1.1.463) (R Core Team, 2019). 


\section{RESULTS}

\section{Germination under field conditions}

318 In the field trials, the germination percentage was significantly different in both years. Splitting

319

320

321

322

323

324

325

326

327

328

329

330

331

332

333

334

335

336

337

338

339

340

341

342

343

344

345

346

347

348

349

350

351

352

353

354 the two years showed that the effects of DIV, Den, and DIV x Den were significant (Table 1). On average of all diversity treatments, the germination was $34.4 \%$ in 2016 in comparison with $54.4 \%$ in 2017. In 2016, increasing seed density reduced germination of AC, BM, and Mix by $13.2 \%, 26.7 \%$, and $39.4 \%$, respectively (Fig. $2 \mathrm{~A}$ ), while in 2017 , gradually increasing seed density reduced the germination of $\mathrm{AC}, \mathrm{BM}$, and the Mix by $20.1 \%, 18.0 \%$, and $33.6 \%$, respectively. Thus, the germination rate was negatively affected by seed density in both years, and in both species and the mixture. In addition, a higher number of weed seedlings were found in 2017 than in 2016.

The absolute mixture effect was significantly different in both years. Specifically, in 2017, a stronger negative AME was observed than in 2016 (Fig. 2B). In 2016, only at 100\% seed density, the AME was significantly negative, i.e. the germination percentage in the mixture was significantly lower than the monocultures by $5 \%$, while, in 2017 , at $100 \%$ and $150 \%$, germination was significantly reduced in the mixture by $5.5 \%$ and $9.4 \%$, respectively (Fig. $2 \mathrm{~B}$ ). The field trial showed no significant deviation GR from 1 in any of the years. In addition, both of the species germinated in the mixture according to the expected ratio, i.e. almost equal to 0.5 (Fig. 2C and 2D) except in 2016, at 50\% seed density, when BM was dominant.

\section{Germination under greenhouse conditions}

In the pot trial, the $D I V$ effect was significant at $\mathrm{p}<0.05$, and the density effect (Den) was almost significant at $\mathrm{p}<0.1$, while the drought effect $(C D)$ did not affect the germination percentage of any of the monocultures and the mixtures (Table 1). At both densities, the germination of $\mathrm{BM}_{\text {mono }}$ was higher than $\mathrm{AC}_{\text {mono }}$ with a difference of $5.2 \%$, on average over all drought intensities (Figs. 3A and 3B). On average of all diversity treatments and drought intensities, increasing seed density reduced the germination by $4 \%$ (Fig. 3G).

The AME was $>0$ and GR $>1$ only at $70 \%$ WHC at high density, showing that the germination in this mixture was improved compared to the monocultures only at this level of water availability, but not at the other conditions (Figs. 3B-3E). On average, AME was positive at both densities and higher at high density but this difference was not significant (Fig. 3H). The change in PGRs of both species at the different drought intensities showed no clear trend (Figs. $3 \mathrm{C}-3 \mathrm{~F})$; however, on average, they were close to 0.5 , showing an equal contribution of $\mathrm{AC}$ and $\mathrm{BM}$ to germination in the mixtures (Fig. 3I).

\section{Germination under laboratory conditions}

In the laboratory trial 1 , the $D I V$ effect was significant at $\mathrm{p}<0.05$, and the $S P A$ effect was almost significant at $\mathrm{p}<0.1$ (Table 2). On average across diversity treatments, the single seed spacing showed higher germination than the double seed spacing by $6.6 \%$. Notably, in the singly seed spacing, the germination of $\mathrm{AC}, \mathrm{BM}$, and the Mix were higher than the double seed spacing by $17.3 \%, 6.8$, and $1.7 \%$ (Fig. 4A). Although AME was not significantly affected by seed spacing, a 
355

356

357

358

359

360

361

362

363

364

365

366

367

368

369

370

371

372

373

374

375

376

377

378

379

380

381

382

383

384

385

386

387

388

389

390

391

392

393

negative AME was observed at single seed spacing, with germination in the mixture being $6.7 \%$ lower than in the average of the monocultures. In contrast, the double seed spacing showed a trend of positive AME, though this was not significantly $>0$ (Fig. 4B). The GR showed that both of the species almost germinated equally in the mixture independent of seed spacing (Fig. 4C).

In the laboratory trial 2, the binomial GLM showed that the $D I V, T, C D, D I V \times T$, and only the interaction of $D I V \times T$ and $C D \times T$ were significant (Table 2). For both species in monoculture and mixture, the highest germination percentage was observed at $20 \%$ of WHC and was significantly higher than $12^{\circ} \mathrm{C}$ and $28^{\circ} \mathrm{C}$ by $25.1 \%$ and $19.9 \%$, respectively (Figs. $5 \mathrm{~A}-5 \mathrm{C}$ ). On average across drought intensities, the germination of $\mathrm{BM}_{\text {mono }}$ was significantly higher than $\mathrm{AC}_{\text {mono }}$ at $12^{\circ} \mathrm{C}$ and $20^{\circ} \mathrm{C}$ by $27.7 \%$ and $21.0 \%$, respectively, but not at $28^{\circ} \mathrm{C}$. In the mixture, the improved germination of both species was temperature dependent. Specifically, at $12^{\circ} \mathrm{C}$, the germination of both species surpassed their monocultures; this effect gradually decreased with increasing temperature until no difference was observed at $28^{\circ} \mathrm{C}$ between the monocultures and the mixture (Figs. 5A-5C).

The results of the AME, GR, and PGRs that have been previously described in Elsalahy et al., 2020 showed specific effects on germination. Specifically, the absolute mixture effect (AME) on germination, i.e. the difference between the observed value in the mixture and the average value of the monocultures was significantly affected by temperature but not by water availability. On average of all drought intensities, the AME at $12^{\circ} \mathrm{C}$ was significantly positive and higher than the $\mathrm{AME}$ at $20^{\circ} \mathrm{C}$ and $28^{\circ} \mathrm{C}$ by $67.0 \%$ and $95.4 \%$, respectively (Fig. 6). Increasing water availability decreased $\mathrm{AME}$ at $12^{\circ} \mathrm{C}$ until the $\mathrm{AME}$ was similar at $100 \% \mathrm{WHC}$ for the three temperatures.

The GR and the PGR ${ }_{\mathrm{BM}}$ were significantly affected by the temperature levels, particularly at $12^{\circ} \mathrm{C}$, GR was $>1$ at the different drought intensities, but this was only significant at $25 \%$ WHC (Fig. 7A). Notably, there was no consistent directional effect of drought intensity on GR. PGR ${ }_{B M}$ showed a clear trend of being reduced by increasing temperature, namely PGR $_{\mathrm{BM}}$ was significant $>0.5$ at $12^{\circ} \mathrm{C}$ (Figs. $7 \mathrm{~A}-7 \mathrm{C}$ ).

\section{DISCUSSION}

Our overall results indicate that mixing legume species may significantly affect seed germination, compared to the monocultures of the two species. However, there was no consistently positive or negative direction of the mixture effect. Instead, we observed both significantly positive and negative responses of germination to mixing the two species. Further, the mixture effect was dependent on other factors, notably temperature level as well as water availability. In particular, there was a significant positive mixture effect at sub-optimal temperature suggesting interspecific facilitation at $12^{\circ} \mathrm{C}$. In the following, we first discuss the effects of species identity on germination, as an important prerequisite to understand effects in the mixtures. We then present potential mechanisms that may underlie these observations and discuss our findings with respect to our initial hypothesis. 
394

395

396

397

398

399

400

401

402

403

404

405

406

407

408

409

410

411

412

413

414

415

416

417

418

419

420

421

422

423

424

425

426

427

428

429

430

431

432

433

We assume that any mixture effects on germination percentage would be caused by interactions among seedlings, not among seeds. The existence of a general mechanism explaining the communication among the seeds prior to emergence would be highly intriguing. However, common sense dictates that relatively inert seeds are less likely to interact physically or chemically, in their surroundings, than the physiologically active seedlings, thus may not affect their neighbors. Unfortunately, the differences between seed and seedling effects on germination cannot be explicitly distinguished in the field.

\section{Effect of species identity on germination}

Under controlled conditions, the germination of $\mathrm{BM}$ was significantly higher at $12^{\circ} \mathrm{C}$ and $20^{\circ} \mathrm{C}$ than at $28^{\circ} \mathrm{C}$ (Figs. $5 \mathrm{~A}$ and $5 \mathrm{~B}$ ). This observation is consistent with the fact that the optimal germination for $\mathrm{BM}$ is between $10^{\circ} \mathrm{C}$ and $20^{\circ} \mathrm{C}$ (Sharpe \& Boyd, 2019) but in contrast to a study stating that the optimum temperature for germination of $\mathrm{BM}$ is $26^{\circ} \mathrm{C}$ (Tribouillois et al., 2016). The sensitivity of BM germination to high temperature is also in contrast with a number of studies that have reported BM to be adapted to warm conditions, though this observation may refer to the response after crop establishment or at later growth stages (Döring et al., 2013; Elsalahy et al., 2019). The ability of $\mathrm{AC}$ to germinate at $12^{\circ} \mathrm{C}$ and $20^{\circ} \mathrm{C}$ was significantly lower than $\mathrm{BM}$ (Figs. 5A and 5B). This observation was in contrast to our expectation as it was supposed for AC to germinate better than BM, specifically at $12^{\circ} \mathrm{C}$ based on its supposed geographic origin in the northern area (Shaeffer, Wells \& Nelson, 2017). In addition, many studies reported the adaptation of AC to cool conditions (Döring \& Boufartigue, 2013; Sheaffer et al., 2003).

The temperature influenced germination percentage but not germination dynamics of both species where both species show the maximum percentage of germination at $20^{\circ} \mathrm{C}$ and decreased at temperatures lower and higher than the maximum temperature (Figs. 5A-5C). This germination dynamic has been reported for several species from the family Fabaceae (Tribouillois et al., 2016). The inability of AC and BM to reach a high percentage of germination at high temperatures (Fig. 5C) is most likely due to the presence of hard seeds in the seed lot (Uzun \& Aydin, 2004). This property is well described for Medicago and Trifolium species, whose hard seed coats may lead to low germination as high temperature deactivates the enzymes required for releasing some volatile compounds that are essential for breaking dormancy (Motsa et al., 2017).

The germination percentage of BM was consistent at all levels of water availability at the optimal temperature level (Fig. 5B), in contrast to a study reporting that germination of most Fabaceae species, among them BM, are sensitive to low water availability and better suited to rainy climates (Tribouillois et al., 2016). The lower germination percentage of AC than of BM under dry conditions (Figs. 2A, 3A-3D, 5A and 5B) is in agreement with some studies reporting AC's sensitivity to dry conditions (Chapman et al., 1990). However, in a recent study by (Elsalahy et al., 2020), it was found that the drought resilience of AC is higher than of BM. This finding indicates that the response of AC to water availability is phenologically dependent i.e., is based on the stages of plant development (Hatfield \& Prueger, 2015). 
434

435

436

437

438

439

440

441

442

443

444

445

446

447

448

449

450

451

452

453

454

455

456

457

458

459

460

461

462

463

464

465

466

467

468

469

470

471

472

In summary, the response of germination to environmental factors (temperature and water availability) differs between the two studied legume species AC and BM, but the complexity of interactions among these abiotic factors makes it difficult to predict which of the species will win the germination race under a given set of environmental circumstances.

\section{Potential ecological mechanisms: How mixing species may affect germination}

There are several potential ecological mechanisms how mixing plant species could affect germination. Several mechanisms have been described for productivity (i.e. plant biomass and grain yield) (Bedoussac et al., 2015), and in principle, some of these mechanisms may also be relevant for germination (Fig. 8).

(1) Compensation: The mechanism of compensation means that if one of the partners in a mixture fails, the other one takes its place. It has been shown to be responsible for stabilizing yields of plant mixtures in response to disease (Creissen et al., 2013), but can also be underlying gains of mean productivity in mixtures. In the context of germination, we assume that one of the partners in a mixture fails to germinate at all, e.g. because of a species-specific pathogen only affecting this partner. If there is intraspecific competition on germination in the non-failing partner, i.e. germination is reduced by high density, and then mixing species leads to relaxed competition in the non-failing partner, so that overall germination is higher in the mixture than in the average of the two monocultures (Fig. 8A). Indeed, we did observe reduced germination at higher seed densities, i.e. negative density dependence, in the field (Fig. 2A) and in the climate chamber (Fig. 4A), suggesting intraspecific competition. Such density dependence of germination has also been found in other species (Tielbörger \& Prasse, 2009), though in some cases positive density dependence has also been found (Leverett, Schieder \& Donohue, 2018). Note that in the context of compensation, the reason for failure can vary, and that in principle it may also locally vary which of the partners in a field is affected by a failure-inducing factor, as long as the spatial zone of competition is considerably smaller than the locally affected area leading the other species to fail. The point is that a locally acting mortality factor only affecting one partner will reduce competition for the remaining partner. A negative mixture effect, however, would be unlikely to emerge from compensation.

(2) Complementation (or complementarity) means that the two partners in a mixture complement each other in their resource use, either spatially or temporally, so that jointly they can use a greater amount of the resource than if they are in single stands. Gaps left by one component are filled by the other one. Evidence for complementation has been presented for various species mixtures (Von Felten \& Schmid, 2008; Hooper, 1998; Xiao et al., 2018). Here we assume that complementation is primarily based on temporal differentiation in resource use as there is (probably) less room for spatial complementarity in the very early stage of plant development; germinating plants may or may not be overlapping in their zones of influence, but a strong spatial differentiation between species, as observed, e.g., for developed root systems or above-ground plant architecture affecting light capture, is, in our view, unlikely in germinating plants. 
473

474

475

476

477

478

479

480

481

482

483

484

485

486

487

488

489

490

491

492

493

494

495

496

497

498

499

500

501

502

503

504

505

506

507

508

509

510

511

512

In this case, this means that there is a fast and slow germinating partner, i.e. there is asynchronous behavior of the two species. Evidence for such interspecific asynchrony is an observed increase in the length of the radical of $\mathrm{BM}$ in comparison with $\mathrm{AC}$ at $12^{\circ} \mathrm{C}$ in the laboratory trial, suggesting a faster germination rate of BM than of AC. As our focus, in the laboratory experiment, was on germination responses rather than on the subsequent seedling growth, we recorded our observations for the asynchronous germination by photos (Fig. S2). Our finding regarding asynchronous germination is consistent with the crop growth rate of $\mathrm{AC}$ and $\mathrm{BM}$ on the base of biomass production, as we have reported in previous studies, that BM is faster growing than AC (Elsalahy et al., 2020). In addition, in both field trials, BM was dominant at the early stage of crop establishment.

For temporal complementation mechanisms to come into force, we need to assume, as for compensation, that density dependent intraspecific competition affects germination, so that with higher seed density germination is reduced within both monocultures. As we have argued above, this assumption of density dependent germination rate is supported by our data. In this case, the faster partner has an increased germination rate in the mixture than in its monoculture, because of relaxed competition, since its slower neighbors in the mixture are not yet competing (phase 1 in Fig. 8B).

The outcome of interest of this scenario, i.e. the mixture effect, will then depend on the relationship between inter- and intraspecific competition in phase 2 when the slow partner germinates, as follows. First, we assume that interspecific competition (blue arrows) and intraspecific competition (red arrows) are equal in size. In that case, it does not matter for the slower partner whether it is neighbored by its own kind as in the monoculture, or by the faster partner as in the mixture, and therefore germination of the slower partner will not be affected by mixing. Because of the increased germination of the faster partner in the mixture than in the monoculture, however, the overall mixture effect will be positive. It is now easy to see that this positive mixture effect can be reduced, and even turn negative, if the size advantage of the faster species in phase 2 leads the slower partner to experience stronger competition from its neighbors than in its own monoculture (Connoily \& Wayne, 1996). In this case, germination of the slower partner will be reduced in the mixture in comparison to its monoculture, and the positive mixture effect on the faster species and the negative effect on the slower species will cancel each other out, or, with a larger relative effect of the outcompeting effect, even lead to negative mixture effects.

(3) Intraspecific asynchrony: Asynchronous germination, as described above for the two species, can also occur within each of the species, notably at lower than optimal temperature. It is expected that with germination more spread out over time because of low temperature (Groot, 2020; Luo et al., 2018), monocultures and mixtures will be differently affected, but that this difference again depends on the relationship between intra- and interspecific competition. Here, we assume that interspecific competition is weaker than intraspecific completion, so that this case falls under the heading of complementation. Then, temporally spread-out germination within a species (intraspecific asynchrony) means that - because of the size advantage of a 
513 neighbor of the same species - germination losses in the monoculture through competition will

514 be higher than if germination is more synchronous (Fig. 8C). However, in the mixture, this effect

515 of asynchrony may be less marked if interspecific competition is weaker than intraspecific

516 competition. This means that for lower temperatures a higher mixture effect on germination

517 could be predicted, and this is indeed what we found in the laboratory experiment with controlled

518 temperature (Fig. 6). However, in the field where temperature levels were markedly lower in

5192017 than in 2016 (Fig. 1B), this expectation was not confirmed as the AME was lower in 2017

520 than in 2016 (Fig. 2B).

521

(4) Competitive effect and response. This mechanism refers to the balance between

522 competitive effect (i.e. how suppressive a species is) and competitive response (i.e. how tolerant

523 it is when faced with competition) (Goldberg \& Landa, 1991). We assume that the two partners

524 in the mixture differ in their competitive traits such that one partner (A) is more suppressive

525

526

527

528

529

530

531

532

533

534

535

536

537

538

539

540

541

542

543

544

545

546

547

548

549

550

551 (high competitive effect on a target plant), but also more sensitive (low tolerance), while the other one (B) is less suppressive, with milder competition towards a target plant, but less sensitive, i.e. exhibiting a more tolerant competitive response (Fig. 8D). Here it can be seen that, as before, the mixture relaxes the competition towards one of the partners, in this case, the more sensitive one, because the immediate neighbor is less suppressive than in the monoculture of the suppressive partner. However, in the mixture, this less suppressive partner is also neighbored by a more suppressive partner than in its monoculture, which could mean that germination of the less suppressive partner is reduced. This case will depend on the relationship between competitive effect and competitive response. If the high tolerance of partner B matches the suppressive competitive effect of partner A, then germination will not be reduced in B. If, on the other hand, the suppressive force is stronger, there will be a reduction of B's germination and a concurrent reduction in the mixture effect.

These considerations also lead to the question of how mixture effects on germination might be influenced by the presence of weeds in the field. Here, the prediction is that the mixture effect will be reduced, i.e. diluted, by the presence of (suppressive) weeds. The likelihood that the more sensitive crop partner is neighbored by weed species with high competitive suppressiveness is the same in the monoculture as in the mixture; however, the relaxation of competition through the absence of a same-species neighbor with high competitive ability will be lost through the weeds' presence. However, in the field, our data was not consistently in line with this prediction, as we observed no clear relationship between weed density and AME (Fig. 2B). Further, completely removing weeds as in the pot trial and in the climate chamber trials, did not consistently lead to higher AME (e.g. Figs. 3H, 4B, 6) than in the field.

(5) Facilitation. A last, currently more speculative, mechanism of interaction between the two species is the production of volatile organic compounds (VOCs) that may promote (or reduce) the germination of one or both species (Motsa et al., 2017). While it is easy to argue that the production of VOCs, their accumulation in the growing medium, or their decomposition rate may have been affected by the varied environmental conditions to explain the (chaotic)

Peer] reviewing PDF | (2020:07:50696:2:0:NEW 23 Nov 2020) 
552 dependency of the mixture effect on the abiotic factors, it is impossible to conclude from our

553

554

555

556

557

558

559

560

561

562

563

564

565

566

567

568

569

570

571

572

573

574

575

576

577

578

579

580

581

582

583

584

585

586

587

588

589

590

591

data whether, or in which ways, VOCs may have been involved in the mixture effects.

\section{CONCLUSIONS}

As our results show, there was no consistent mixture effect on germination. However, we did find significant effects of mixing on germination, both positive and negative, under some experimental conditions.

It is not possible to infer causality from our experiments in relation to the observed effects of mixing species on germination. However, as we have argued in the discussion, there are several potential mechanisms that may, when combined, explain both directions of mixture effects on germination. At the same time, the ecological interactions that may be involved in these mechanisms are complex and sometimes even difficult to measure at the spatial scale that is relevant for germinating seeds. This means that it may be almost impossible to predict, under realistic field conditions, the direction and size of mixture effects on germinating (crop) plants. This may be different when more dissimilar plant species are combined, or when severe stress factors only affect one of the partners in the mixture. Future research dealing with mixing effects on germination should, therefore, focus on these conditions. In this case, we suggest that it will be increasingly important to understand the compensation ability of the partner species in monocultures and mixtures. Our research has highlighted that mixture effects may depend on environmental conditions, though not in easily predictable ways. If and insofar as this general observation is also valid for mixture effects on yields, it will be necessary to re-think strategies for optimizing crop mixtures for use on individual farms. In this case, it will be necessary to create resources for farmers to help them to adopt and adapt this practice to their own farm context.

\section{AUTHOR CONTRIBUTIONS}

- Heba Elsalahy and Thomas Döring conceived and designed the experiments, conducted the experiments, collected the data, performed the statistical tests, and wrote the manuscript.

- Thomas Döring provided the facilities and advised on the preparation of materials.

- Sonoko Bellingrath-Kimura and Timo Kautz read and edited the manuscript.

- All authors approved the final manuscript.

\section{ACKNOWLEDGEMENTS}

The Yousef Jameel Scholarship at Humboldt University, Berlin, Germany, and the Ekhaga Foundation are greatly appreciated for their financial support. We also thank the Nicolai Schmidt, Gero Carus, Cansu Cali, Manuel Müller, Anne Donath and the staff at the HumboldtUniversity, department of Agronomy and Crop Science for support during the experiments.

\section{CONFLICTS OF INTEREST}

The authors declare no competing interests. 
592 REFERENCES

593 Agricultural Climatology of the Humboldt-University of Berlin. Available online:

594

595

596

597

598

599

600

601

602

603

604

605

606

607

608

609

610

611

612

613

614

615

616

617

618

619

620

621

622

623

624

625

626

627

628

629

630

631

632

633

634

635

636

637 on 15.09.2019).

Aponte A, Samarappuli D, Berti MT. 2019. Alfalfa-grass mixtures in comparison to grass and alfalfa monocultures. Agronomy Journal 111:628-638. DOI: 10.2134/agronj2017.12.0753.

Bedoussac L, Journet EP, Hauggaard-Nielsen H, Naudin C, Corre-Hellou G, Jensen ES, Prieur L, Justes E. 2015. Ecological principles underlying the increase of productivity achieved by cereal-grain legume intercrops in organic farming. A review. Agronomy for Sustainable Development 35:911-935. DOI: 10.1007/s13593-014-0277-7.

Bélanger G, Tremblay GF, Papadopoulos YA, Duynisveld J, Lajeunesse J, Lafrenière C, Fillmore SAE. 2017. Yield and nutritive value of binary legume-grass mixtures under grazing or frequent cutting. Canadian Journal of Plant Science 98:395-407. DOI: 10.1139/CJPS-2017-0183.

Bergelson J, Perry R. 1989. Interspecific Competition Between Seeds : Relative Planting Date and Density Affect Seedling Emergence. Ecology 70:1639-1644.

Brady NC, Weil RR. 2002. The Nature and Properties of Soils. 13th Edn., Pearson Education, Inc., New Jersey:127-132.

Burnham KP, Anderson DR, Huyvaert KP. 2011. AIC model selection and multimodel inference in behavioral ecology: Some background, observations, and comparisons. Behavioral Ecology and Sociobiology 65:23-35. DOI: 10.1007/s00265-010-1029-6.

Butler TJ, Celen AE, Webb SL, Krstic D, Interrante SM. 2014. Temperature affects the germination of forage legume seeds. Crop Science 54:2846-2853. DOI: 10.2135/cropsci2014.01.0063.

Chapman HM, Dodds KG, Keoghan JM. 1990. Evaluation of the agronomic potential of pasture legume introductions on droughty outwash soils. New Zealand Journal of Agricultural Research 33:21-27. DOI: 10.1080/00288233.1990.10430657.

Cherney JH, Smith SR, Sheaffer CC, Cherney DJR. 2020. Nutritive value and yield of reducedlignin alfalfa cultivars in monoculture and in binary mixtures with perennial grass. Agronomy Journal 112:352-367. DOI: 10.1002/agj2.20045.

Connoily J, Wayne P. 1996. Asymmetric competition between plant species. Oecologia 108:311-320. DOI: 10.1046/j.0269-8463.2001.00558.x.

Creissen HE, Jorgensen TH, Brown JKMM. 2013. Stabilization of yield in plant genotype mixtures through compensation rather than complementation. Annals of Botany 112:14391447. DOI: $10.1093 / \mathrm{aob} / \mathrm{mct} 209$.

Döring TF, Baddeley JA, Brown R, Collins R, Crowley O, Cuttle S, Howlett SA, Jones HE, Mccalman H, Measures M, Pearce BD, Pearce H, Roderick S, Stobart R, Storkey J, Tilston EL, Topp K, Watson C, Winkler LR, Wolfe MS. 2013. Using legume-based mixtures to enhance the nitrogen use efficiency and economic viability of cropping systems: Project Report (RD-2007-3447). HGCA/Agric. Hort. Dev. Board.:190 pp. DOI: 10.1016/j.talanta.2010.11.025.

Döring T, Boufartigue C. 2013. Manifold green manures - Part II: Alsike and crimson clovers. Organic Grower 23:28-29.

Effah E, Holopainen JK, McCormick AC. 2019. Potential roles of volatile organic compounds in plant competition. Perspectives in Plant Ecology, Evolution and Systematics 38:58-63. DOI: 10.1016/j.ppees.2019.04.003. 
638 Elsalahy HH, Bellingrath-kimura SD, Roß C, Kautz T, Döring TF. 2020. Crop Resilience to 639 Drought With and Without Response Diversity. Frontiers in Plant Science 11:1-12. DOI: $640 \quad 10.3389 /$ fpls.2020.00721.

641 Elsalahy H, Döring T, Bellingrath-Kimura S, Arends D. 2019. Weed Suppression in Only-

$642 \quad$ Legume Cover Crop Mixtures. Agronomy 9:648. DOI: 10.3390/agronomy9100648.

643

644

645

646

647

648

649

650

651

652

653

654

655

656

657

658

659

660

661

662

663

664

665

666

667

668

669

670

671

672

673

674

675

676

677

678

679

680

681

682

683

FAO. 2020. Ecocrop, Data Sheet, black medic (Medicago Lupulina). Available online: http://ecocrop.fao.org/ecocrop/srv/en/dataSheet?id=7654 (accessed on 15.06.2020).

Von Felten S, Schmid B. 2008. Complementarity among species in horizontal versus vertical rooting space. Journal of Plant Ecology 1:33-41. DOI: 10.1093/jpe/rtm006.

Fenesi A, Kelemen K, Sándor D, Ruprecht E. 2020. Influential neighbours: Seeds of dominant species affect the germination of common grassland species. Journal of Vegetation Science:1028-1038. DOI: 10.1111/jvs.12892.

Fincheira P, Parada M, Quiroz A. 2017. Volatile organic compounds stimulate plant growing and seed germination of Lactuca sativa. Journal of Soil Science and Plant Nutrition 17:853867. DOI: $10.4067 / \mathrm{S} 0718-95162017000400002$.

Goldberg DE, Landa K. 1991. Competitive Effect and Response: Hierarchies and Correlated Traits in the Early Stages of Competition. The Journal of Ecology 79:1013. DOI: $10.2307 / 2261095$.

Groot SPC. 2020. Seed Science and Technology. Volume 48 Issue 1 (2020). Seed Science and Technology 48:133-142. DOI: 10.15258/sst.2020.48.1.14.

Hartmann S, Lunenberg T. 2013. Schwedenklee - Trifolium hybridum L. (engl.: hybrid clover). http://www.lfl.bayern.de/ipz/gruenland/027753/index.php (accessed on 01.07.2020).

Hatfield JL, Prueger JH. 2015. Temperature extremes: Effect on plant growth and development. Weather and Climate Extremes 10:4-10. DOI: 10.1016/j.wace.2015.08.001.

Hooper DU. 1998. The role of complementarity and competition in ecosystem responses to variation in plant diversity. Ecology 79:704-719. DOI: 10.1890/00129658(1998)079[0704:TROCAC]2.0.CO;2.

Kahnt G. 2008. Leguminosen im konventionellen und ökologischen Landbau. Frankfurt a.M., Germany: DLG Verlag.

Komainda M, Küchenmeister K, Küchenmeister F, Breitsameter L, Wrage-Mönnig N, Kayser M, Isselstein J. 2019. Forage legumes for future dry climates: Lower relative biomass losses of minor forage legumes compared to Trifolium repens under conditions of periodic drought stress. J Agro Crop Sci. 2019 20:460-469. DOI: 10.1111/jac.12337.

Leverett LD, Schieder GF, Donohue K. 2018. The fitness benefits of germinating later than neighbors. American Journal of Botany 105:20-30. DOI: 10.1002/ajb2.1004.

Luo T, Xian M, Khan MN, Hu L, Xu Z. 2018. Precipitation-Driven Changes in Biomass Allocation Pattern for Forests in China. Int. J. Agric. Biol 20:524-530. DOI: 10.17957/IJAB/15.0.

De Mendiburu F. 2019. Agricolae: Statistical Procedures for Agricultural Research. R package version 1.3-0. https://CRAN.R-project.org/package=agricolae (accessed on 15.09.2019).

Mori AS, Furukawa T, Sasaki T. 2013. Response diversity determines the resilience of ecosystems to environmental change. Biological Reviews 88:349-364. DOI: 10.1111/brv.12004.

Motsa MM, Slabbert MM, Bester C, Mokwena L, Taylor M. 2017. Volatile organic compounds from germinating seeds of Cyclopia species as affected by temperature. Seed Science and Technology 45:43-55. DOI: 10.15258/sst.2017.45.1.22. 
684 Nation PN. 1989. Alsike clover poisoning: A review. Canadian Veterinary Journal 30:410-415.

685 Nguyen BT, Lehmann J. 2009. Black carbon decomposition under varying water regimes.

686

687

688

689

690

691

692

693

694

695

696

697

698

699

700

701

702

703

704

705

706

707

708

709

710

711

712

713

714

715

716

717

718

719

720

721

722

723

724

725

726

727

728
Organic Geochemistry 40:846-853. DOI: 10.1016/j.orggeochem.2009.05.004.

Pinheiro J, Bates D, DebRoy S, Sarkar D, Team RC. 2018. nlme: Linear and Nonlinear Mixed Effects Models_. R package version 3.1-137, <URL: https://CRAN.Rproject.org/package $=$ nlme $>$.

R Core Team. 2019. R: A language and environment for statistical computing. R Foundation for Statistical Computing, Vienna, Austria. URL https://www.R-project.org/.

Sales NM, Pérez-García F, Silveira FAO. 2013. Consistent variation in seed germination across an environmental gradient in a Neotropical savanna. South African Journal of Botany 87:129-133. DOI: 10.1016/j.sajb.2013.04.001.

Shaeffer CC, Wells MS, Nelson CJ. 2017. Legumes for northern areas. Forages: An Introduction to Grassland Agriculture:117-131.

Sharpe SM, Boyd NS. 2019. Black Medic (Medicago lupulina) Germination Response to Temperature and Osmotic Potential, and a Novel Growing Degree-Day Accounting Restriction for Heat-Limited Germination. Weed Science 67:246-252. DOI: 10.1017/wsc.2018.68.

Sheaffer CC, Ehlke NJ, Albrecht KA, Peterson PR. 2003. Forage Legumes: Clovers, Birdsfoot Trefoil, Cicer Milkvetch, Crownvetch and Alfalfa, 2nd ed.; Agricultural Experiment Station: Saint Paul, Minnesota. In: pp.608-2003.

Stagnari F, Maggio A, Galieni A, Pisante M. 2017. Multiple benefits of legumes for agriculture sustainability: an overview. Chemical and Biological Technologies in Agriculture 4:1-13. DOI: 10.1186/s40538-016-0085-1.

Storkey J, Döring T, Baddeley J, Collins R, Roderick S, Stobart R, Jones H, Watson C. 2015. A framework for designing multi-functional cover crops. Aspects of Applied Biology 129:712.

Tielbörger K, Prasse R. 2009. Do seeds sense each other? Testing for density-dependent germination in desert perennial plants. Oikos 118:792-800. DOI: 10.1111/j.16000706.2008.17175.x.

Tribouillois H, Dürr C, Demilly D, Wagner MH, Justes E. 2016. Determination of germination response to temperature and water potential for a wide range of cover crop species and related functional groups. PLOS ONE 11:1-16. DOI: 10.1371/journal.pone.0161185.

Uzun F, Aydin I. 2004. Improving Germination Rate of Medicago and Trifolium Species. Asian Journal of Plant Sciences 3:714-717. DOI: 10.3923/ajps.2004.714.717.

Verdú M, Traveset A. 2005. Early emergence enhances plant fitness: A phylogenetically controlled meta-analysis. Ecology 86:1385-1394. DOI: 10.1890/04-1647.

Waldron BL, Bingham TJ, Creech JE, Peel MD, Miller R, Jensen KB, ZoBell DR, Eun JS, Heaton K, Snyder DL. 2020. Binary mixtures of alfalfa and birdsfoot trefoil with tall fescue: Herbage traits associated with the improved growth performance of beef steers. Grassland Science 66:74-87. DOI: 10.1111/grs.12257.

Xiao J, Yin X, Ren J, Zhang M, Tang L, Zheng Y. 2018. Complementation drives higher growth rate and yield of wheat and saves nitrogen fertilizer in wheat and faba bean intercropping. Field Crops Research 221:119-129. DOI: 10.1016/j.fcr.2017.12.009.

Peer) reviewing PDF | (2020:07:50696:2:0:NEW 23 Nov 2020) 
Figure 1

Cumulative water applied per pot (CWA; $A)$ in the pot trial and the cumulative precipitation (Cum.Pre; $B$ ) in two field trials after fifteen days of sowing.

The pot trial started on $1^{\text {st }}$ June 2016 and included six intensities of cumulative drought: $100 \%, 85 \%, 70 \%, 55 \%, 40 \%$, and $25 \%$ water holding capacity (WHC). The two field experiments were conducted on the 29th and 25th of April in 2016 and 2017, respectively. The mean daily temperature (Mean Temp.) is represented in solid line for 2016 and in the dotted line for 2017.
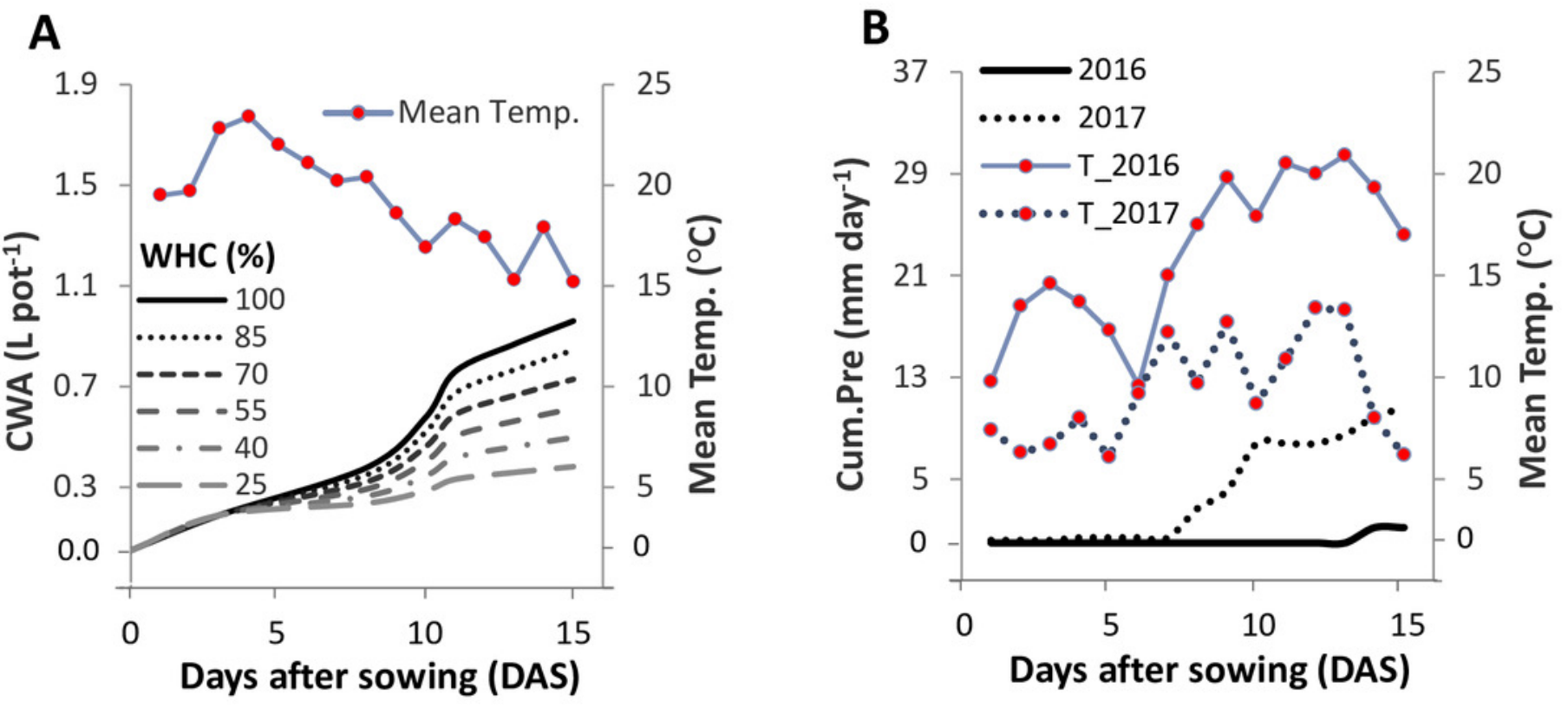


\section{Figure 2}

Germination of alsike clover (AC) and black medic (BM) in monocultures, and a 1:1 mixture (Mix) of the two species in two field trials conducted in 2016 and 2017.

Germination percentage (\%; $A$ and $B$ ), absolute mixture effect (AME; C and D), and partial germination ratio of both species (PGR; E and F) are calculated for seeds sown at three seed densities ( $50 \%, 100 \%$, and $150 \%$ of recommended seed density). The boxes of the boxplot represent the median, and 25th and 75th percentiles, whereas whiskers represent the maximum and minimum values. The absolute mixture effect was calculated by Eq. (1); the dots above each column represent the number of germinated weeds $\mathrm{m}^{-2}$. Negative values indicate a negative mixture effect on germination and vertical bars represent SE of $n=24$ and 36 in 2016 and 2017, respectively. Different letters above bars indicate significant differences among monocultures and the mixture. Asterisks indicate significant mixture effect on germination according to ANOVA; $* * *=\mathrm{P}<0.001, * *=\mathrm{P}<0.01, *=\mathrm{P}<0.05$. The partial germination ratio was calculated by Eq. (2); the solid grey line corresponds to a GR = 1 and the broken green line represents the expected PGR for the mixture (0.5). 

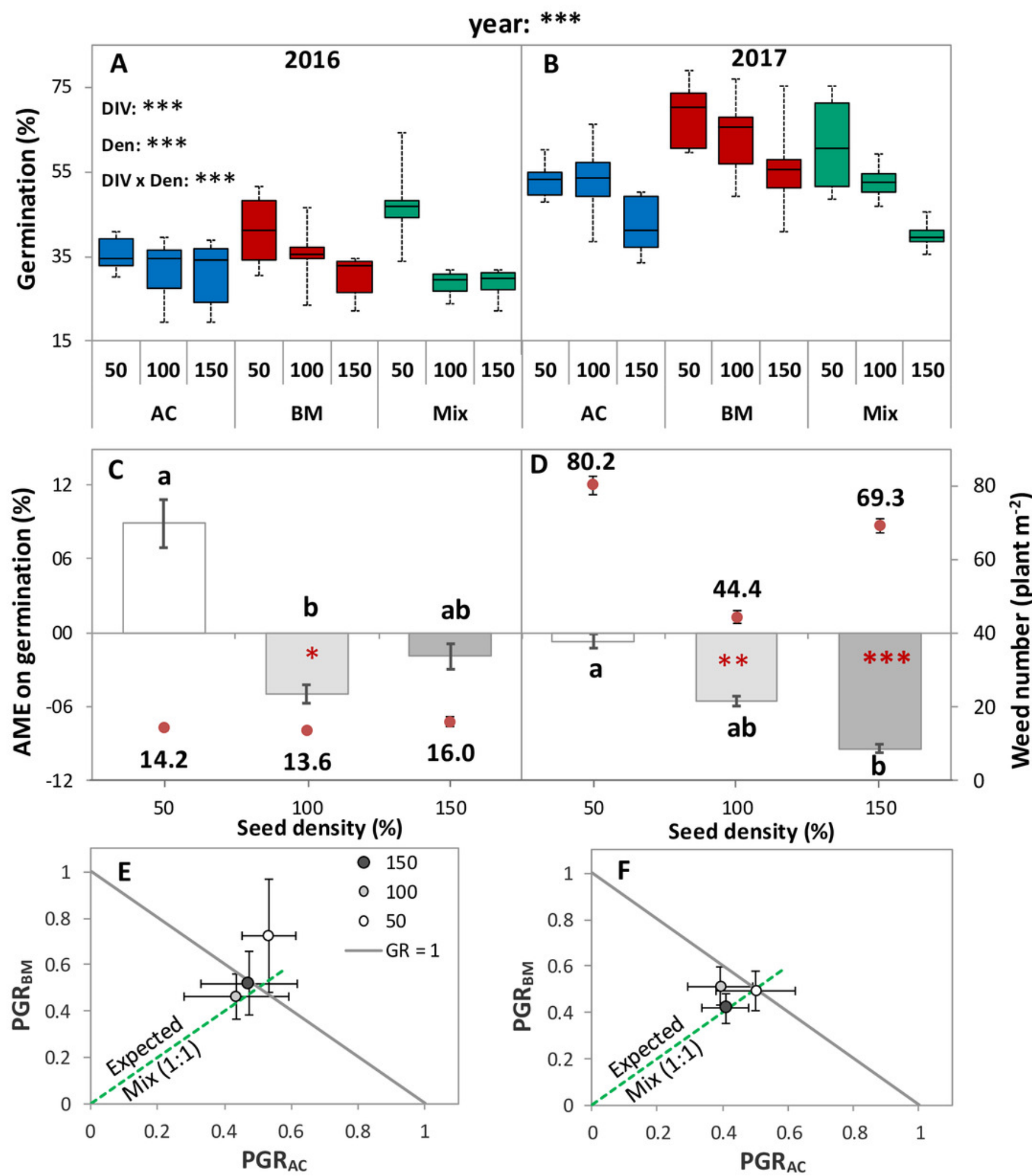


\section{Figure 3}

Germination of alsike clover (AC) and black medic (BM) in monocultures, and a 1:1 mixture (Mix) of the two species in a pot trial.

Germination percentage (\%; A, D, and G), absolute mixture effect (AME; B, E, and H), and partial germination ratio of both species (PGR; C, F, and I) are calculated for seeds sown at two seed densities: high density of 24 seed pot -1 (A-C) and low seed density of 12 seed pot -1 (D-F) under six intensities of cumulative drought (CD; $100 \%, 85 \%, 70 \%, 55 \%, 40 \%$, and $25 \% \mathrm{WHC}$ ). The observed germination is represented in symbols and the fitted curves (Eq. 3) are in lines $(n=4)$; vertical bars represent Tukey's HSD $(p<0.05)$ among the monocultures (mono) and the mixtures (Mix) at a given WHC (A and D). Different letters above the vertical bars represent Tukey's HSD $(p<0.05)$ for the differences among the WHC $(\%)$. Asterisks indicate significant effects of the $D I V, C D$, and $D I V \times C D$ according to ANOVA; ** $=\mathrm{P}<0.01$, * $=\mathrm{P}<0.05, \mathrm{~ns}=$ not significant. The absolute mixture effect was calculated by Eq. (1); the drought intensities were visualized in black gradient color. Positive values indicate a positive mixture effect. The Partial germination ratio was calculated by Eq. (2); the solid grey lines and the broken green lines as in Fig. 2. Asterisks above some data points represent a significant increase in GR $>1$ according to Welch's t-test. 

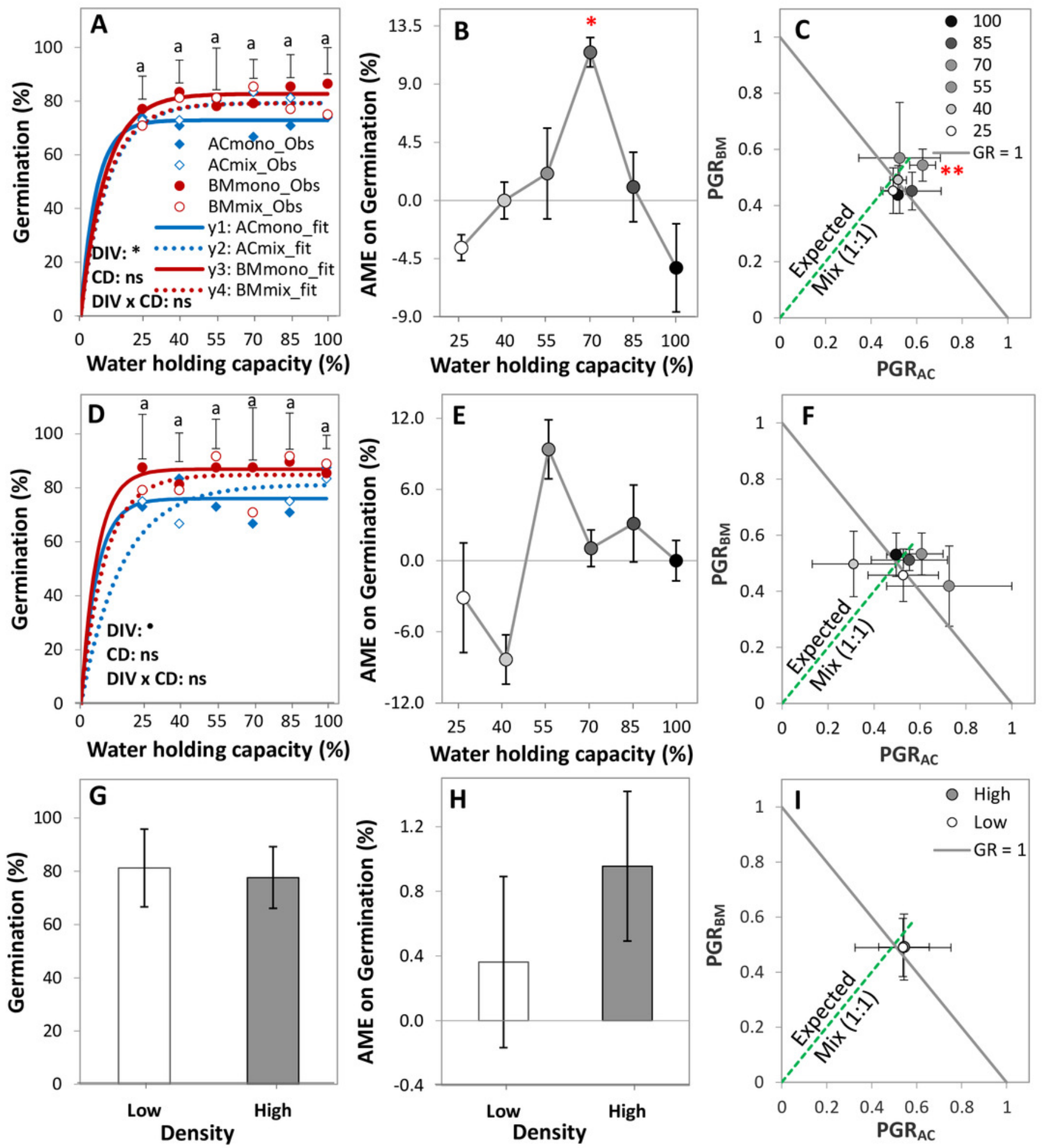


\section{Figure 4}

Germination percentage of alsike clover ( $A C)$, black medic $(B M)$, and a 1:1 mixture (Mix) of the two species (A), absolute mixture effect on germination (AME; $B$ ), and partial germination ratio of both species (PGR; C) in the laboratory trial 1.

The seeds were sown (18 seed tray ${ }^{-1}$ ) in a single (distance between each seed $=1 \mathrm{~cm}$ ) and double (two seeds in pairs) spacing (SPA). The boxes of the boxplot represent the median, and 25th and 75th percentiles, whereas whiskers represent the maximum and minimum values. Asterisks indicate significant effects based on ANOVA results of the generalized linear model of DIV, SPA, and DIV $\times S P A ; * * \mathrm{P}<0.01, * \mathrm{P}<0.05, \cdot \mathrm{P}<0.1$, and $\mathrm{ns}=$ not significant. The absolute mixture effect was calculated by Eq. (1). Positive values indicate positive mixture effects and vertical bars represent standard error of $n=12$. Partial germination ratio was calculated by Eq. (2); the solid grey lines and the broken green lines as in Fig. 2.

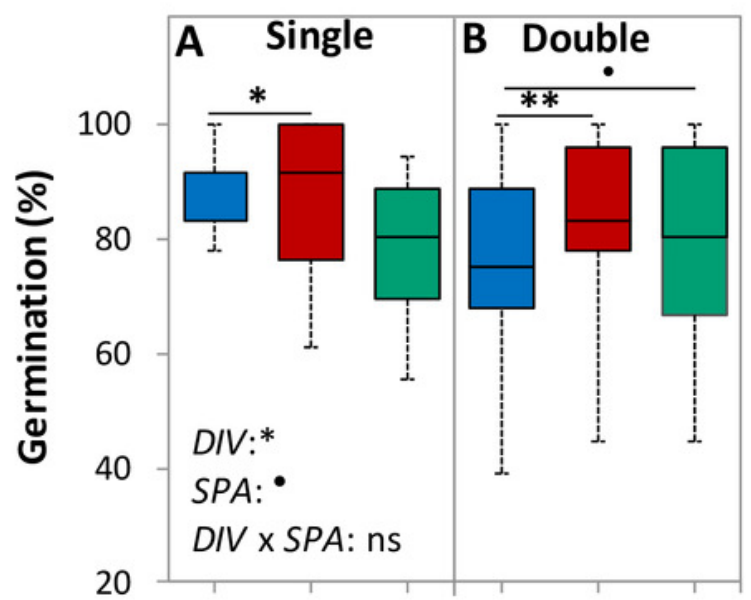

AC BM Mix AC BM Mix
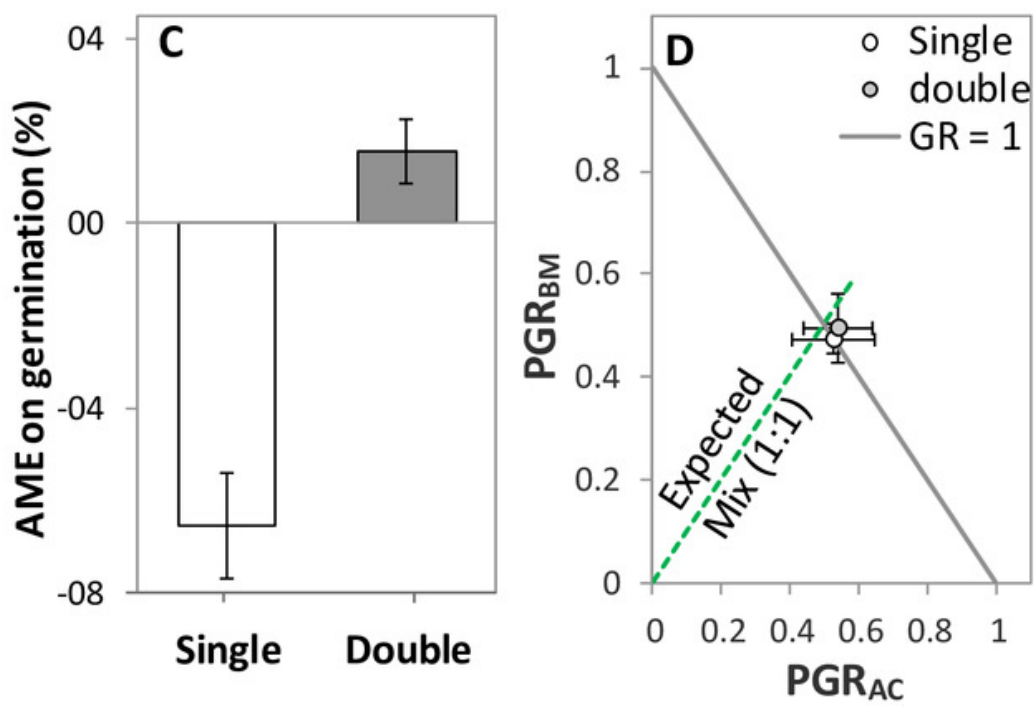


\section{Figure 5}

Germination percentage of alsike clover (AC) and black medic (BM) in monocultures and a 1:1 mixture of the two species in response to four drought intensities and three temperature levels.

The drought intensities $(C D)$ represent $100 \%, 75 \%, 50 \%$, and $25 \%$ of water holding capacity (WHC) and the three temperature levels represent $12^{\circ} \mathrm{C}(\mathrm{A}), 20^{\circ} \mathrm{C}(\mathrm{B})$, and $28^{\circ} \mathrm{C}(\mathrm{C})$. Symbols represent the observed germination $(n=12)$ and lines represent the fitted curves by Eq. 3 . Vertical bars represent Tukey's HSD $(p<0.05)$ for the differences among the two species in the monocultures (mono) and mixture (mix) at a given WHC (\%). Different letters above the vertical bars represent Tukey's HSD $(p<0.05)$ and indicate significant differences among the WHC. Asterisks indicate significant effects of the $D I V, C D$, and $D I V \times C D$ according to ANOVA; $* * *=\mathrm{P}<0.001, * *=\mathrm{P}<0.01, *=\mathrm{P}<0.05, \mathrm{~ns}=$ not significant. 
$12{ }^{\circ} \mathrm{C}$

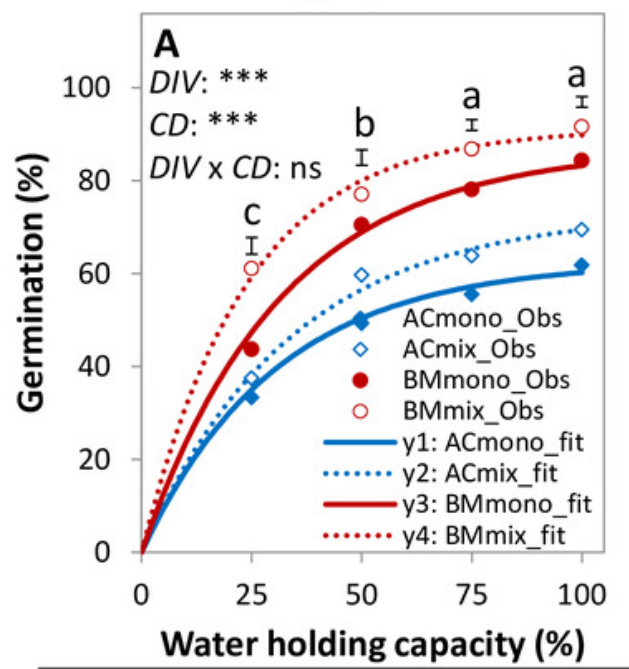

$20^{\circ} \mathrm{C}$

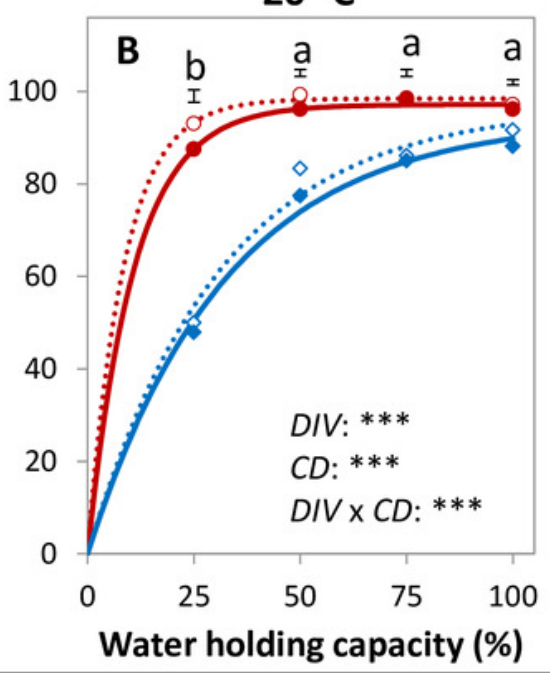

$28^{\circ} \mathrm{C}$

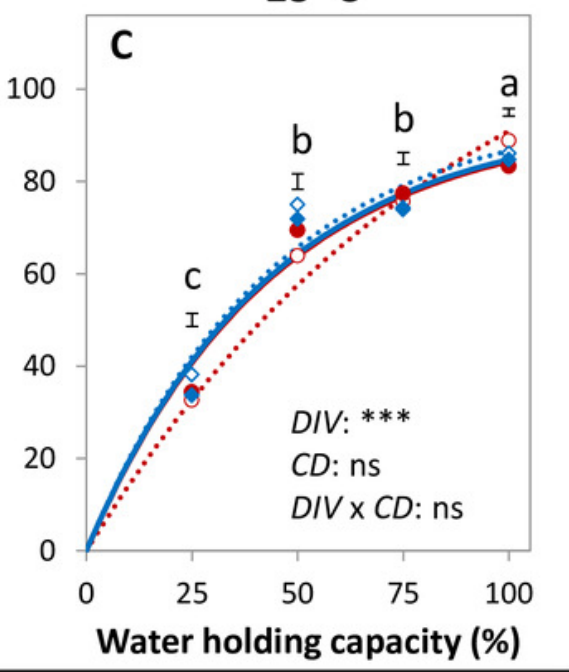

\begin{tabular}{|c|c|c|c|c|c|c|c|c|c|c|c|c|}
\hline \multicolumn{13}{|l|}{ DIV } \\
\hline DF & 3,44 & 3,44 & 3,44 & 3,44 & 3,44 & 3,44 & 3,44 & 3,44 & 3,44 & 3,44 & 3,44 & 3,44 \\
\hline F-value & 4.483 & 5.56 & 13.93 & 14.29 & 32.33 & 19.51 & 10.53 & 5.643 & 2.659 & 0.77 & 0.156 & 0.873 \\
\hline p-value & $0.01^{* *}$ & $0.003 * *$ & $<.001^{* * *}$ & $<.001^{* * *}$ & $<.001^{* * *}$ & $<.001 * * *$ & $<.001^{* * *}$ & $0.002^{* * *}$ & 0.06 & 0.772 & 0.92 & 0.5 \\
\hline AC_mono & $\mathrm{b}$ & $\mathrm{b}$ & $\mathrm{C}$ & $b$ & $\mathrm{~b}$ & $b$ & $\mathrm{~b}$ & $\mathrm{~b}$ & $a$ & $a$ & $a$ & $a$ \\
\hline AC_mix & $b$ & $a b$ & bc & $b$ & $b$ & $b$ & $b$ & $a b$ & a & a & a & a \\
\hline BM_mono & $a b$ & a & $a b$ & a & a & a & a & a & a & a & a & a \\
\hline BM_mix & $\mathrm{a}$ & a & $\mathrm{a}$ & a & a & a & a & a & a & a & a & a \\
\hline \multicolumn{13}{|c|}{$y 1=63\left(1-\exp \left(-0.03^{*} W H C\right)\right), R^{2}=0.79$} \\
\hline$y 2=73(1$ & $1-\exp (-$ & $0.03 * \mathrm{WH}$ & (C)), $R^{2}=0$ & & $97(1-\exp$ & $(-0.03 * W$ & HC)), $R^{2}=0$ & 0.80 & $5(1-\mathrm{ex}$ & $\left(-0.02^{*}\right.$ & NHC)), & ${ }^{2}=0.88$ \\
\hline$y 3=87$ & $1-\exp (-$ & $0.03 * \mathrm{WH}$ & 4C)), $R^{2}=0$ & & 97 (1 - exp & $(-0.09 * W$ & $(H C)), R^{2}=$ & $y 3=c$ & $4(1-$ ex & $\left(-0.02^{*}\right.$ & NHC)), & $2^{2}=0.89$ \\
\hline $\mathrm{y} 4=91$ & $1-\exp (-$ & $0.04 * W H$ & (C)), $R^{2}=0$ & .70 & $98(1-\exp$ & $(-0.12 * W$ & $H C)), R^{2}=$ & $y 4=$ & $37(1-\epsilon$ & $p(-0.01$ & $\left.\left.{ }^{*} \mathrm{WHC}\right)\right)$ & $R^{2}=0.87$ \\
\hline
\end{tabular}




\section{Figure 6}

Absolute mixture effect (AME) on germination (\%) of alsike clover (AC) and black medic (BM) in a 1:1 mixture of the two species in response to four drought intensities and three temperature levels.

The drought intensities $(C D)$ represent $100 \%, 75 \%, 50 \%$, and $25 \%$ of water holding capacity (WHC) and the three temperature levels represent $12^{\circ} \mathrm{C}(\mathrm{A}), 20^{\circ} \mathrm{C}(\mathrm{B})$, and $28^{\circ} \mathrm{C}(\mathrm{C})$. The absolute mixture effect was calculated by Eq. (1); positive values indicate a positive mixture effect. Vertical bars represent Tukey's HSD $(p<0.05)$ among the different temperature levels at a given WHC (\%) of $n=12$. Different letters next to the observed data of the temperature levels indicate significant differences on average of all the drought intensities, based on Tukey's HSD $(p<0.05)$. Asterisks indicate significant effects of the $T, C D$, and $T \mathrm{x}$ $C D$ according to $A N O V A ; * * *=P<0.001$, ns $=$ not significant. 


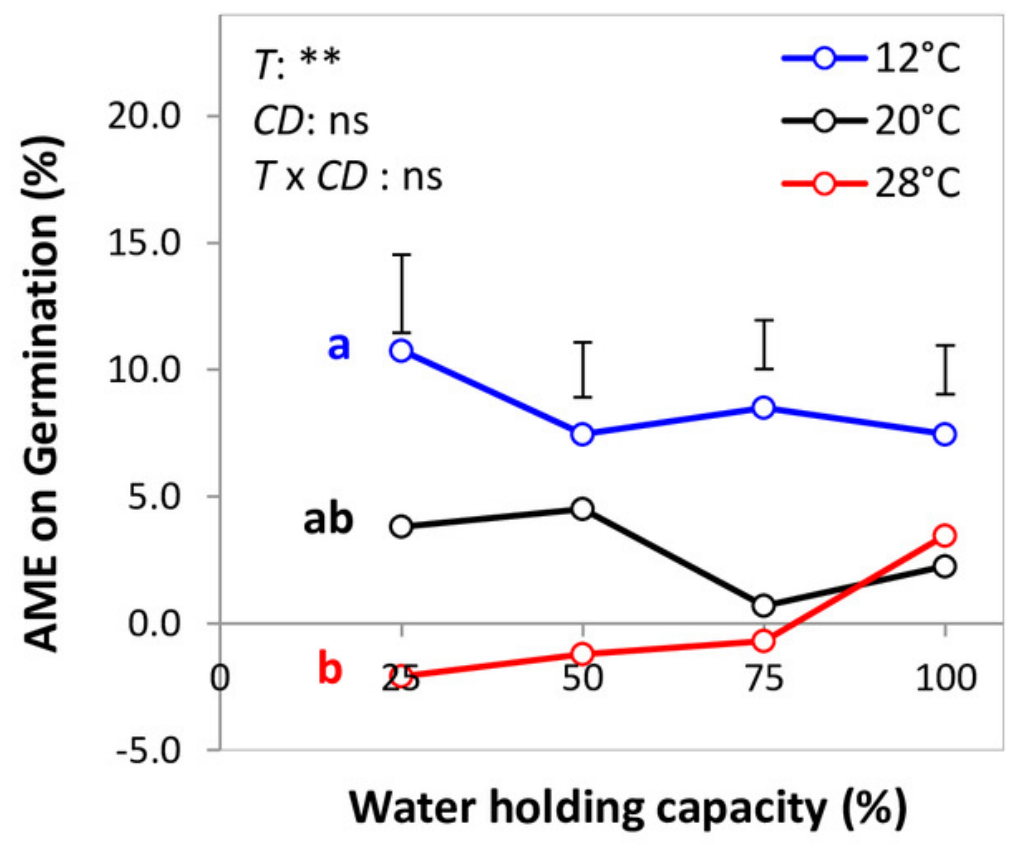




\section{Figure 7}

Partial germination ratio of alsike clover $\left(\mathrm{PGR}_{\mathrm{AC}}\right)$ and black medic $\left(\mathrm{PGR}_{\mathrm{BM}}\right)$ in a 1:1 mixture of the two species in response to four drought intensities and three temperature levels.

The drought intensities $(C D)$ represent $100 \%, 75 \%, 50 \%$, and $25 \%$ of water holding capacity (WHC) and the three temperature levels represent $12^{\circ} \mathrm{C}(\mathrm{A}), 20^{\circ} \mathrm{C}(\mathrm{B})$, and $28^{\circ} \mathrm{C}(\mathrm{C})$. The drought intensities are visualized in black gradient color. The solid grey lines correspond to a $\mathrm{GR}=1$ and the broken green lines correspond to the expected PGR for the mixture. Asterisks above some data points represent a significant increase in $G R>1(P<0.05)$ according to Welch's t-test; $* \mathrm{P}<0.05$.
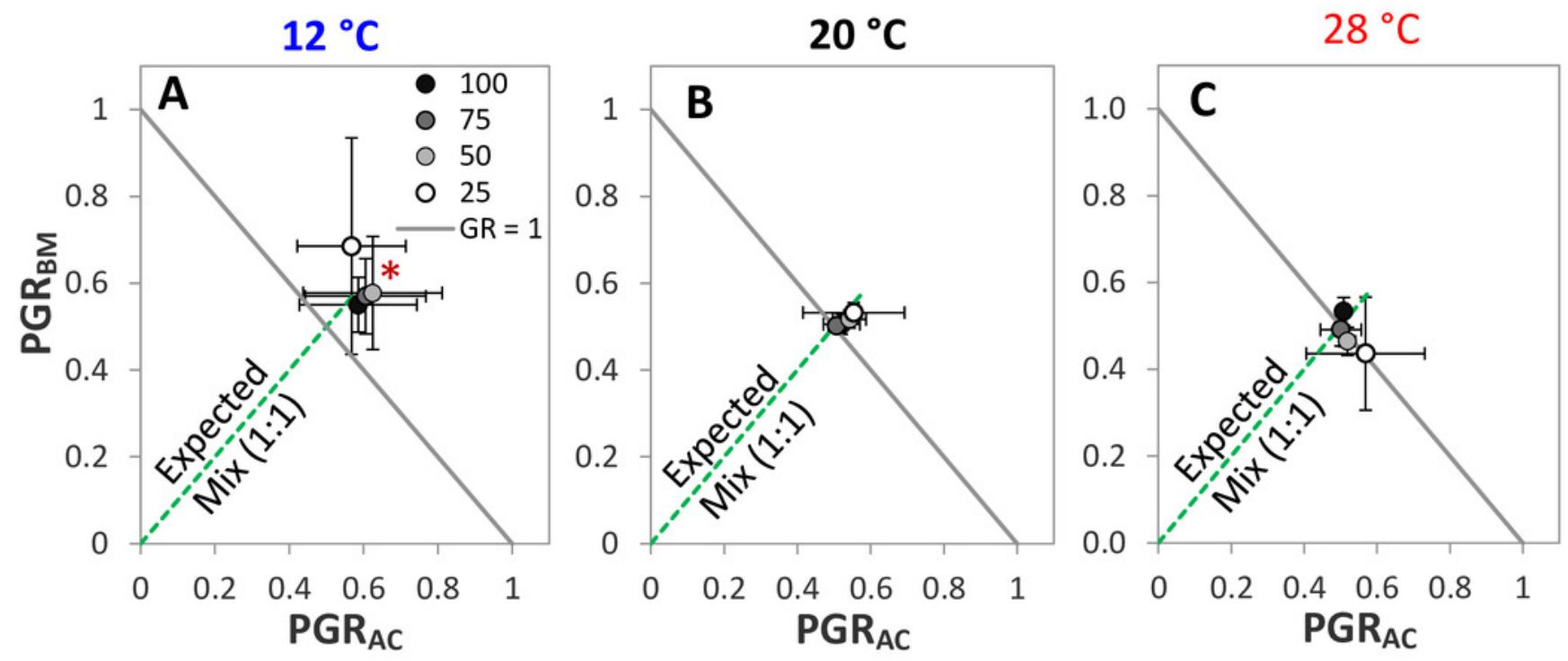
Figure 8

Schematic illustrations describe mechanisms of mixture effect on germination.

Interspecific competition is represented in blue arrows and intraspecific represented in red arrows competition; further explanations are in the text.

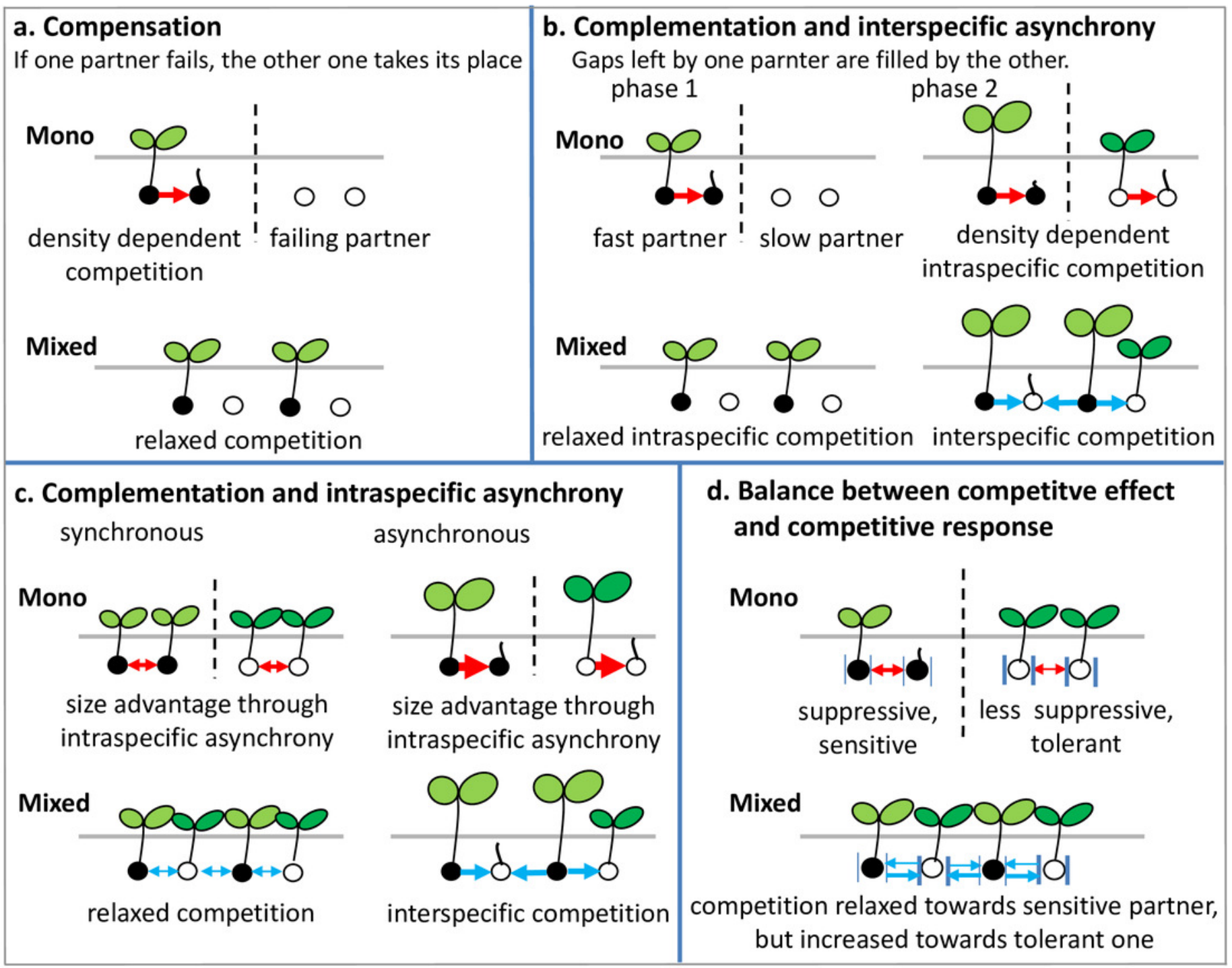




\section{Table $\mathbf{1}$ (on next page)}

Analysis of deviance on effects fitted to seed germination of $A C$ and $B M$ and a 1:1 mixture of the two species in the field and pot trials.

The analysis used a GLM with binomial error distribution and probit link function. 


\begin{tabular}{|c|c|c|c|c|c|c|c|}
\hline Experiment & Model & DF & Deviance & $\begin{array}{c}\text { Residual } \\
\text { DF }\end{array}$ & $\begin{array}{l}\text { Residual } \\
\text { deviance }\end{array}$ & F-value & P-value \\
\hline \multirow[t]{8}{*}{ Two fields } & NULL & & & 647 & 81590.0 & & \\
\hline & Plant diversity (DIV) & 2 & 5842.2 & 645 & 75747.0 & 2921.1 & $<0.0001 * * *$ \\
\hline & Density (Den) & 2 & 7280.9 & 643 & 68467.0 & 3640.5 & $<0.0001 * * *$ \\
\hline & Year $(Y)$ & 1 & 25498.2 & 642 & 42968.0 & 25498.2 & $<0.0001 * * *$ \\
\hline & DIV x Den & 4 & 787.4 & 638 & 42181.0 & 196.9 & $<0.0001 * * *$ \\
\hline & DIV x Y & 2 & 1741.1 & 636 & 40440.0 & 870.5 & $<0.0001 * * *$ \\
\hline & Den $\mathrm{x} Y$ & 2 & 706.3 & 634 & 39734.0 & 353.2 & $<0.0001 * * *$ \\
\hline & DIV x Den x Y & 4 & 305.3 & 630 & 39428.0 & 76.3 & $<0.0001 * * *$ \\
\hline \multirow[t]{4}{*}{ Field_2016 } & NULL & & & 323 & 8461.2 & & \\
\hline & Plant diversity (DIV) & 2 & 190.9 & 321 & 8270.3 & 95.5 & $<0.0001 * * *$ \\
\hline & Density (Den) & 2 & 9.1 & 319 & 8261.1 & 4.6 & $0.01 *$ \\
\hline & DIV x Den & 4 & 72.6 & 315 & 8188.6 & 18.1 & $0.0 * * *$ \\
\hline \multirow[t]{4}{*}{ Field_2017 } & NULL & & & 755 & 44131.0 & & \\
\hline & Plant diversity (DIV) & 2 & 1280.9 & 753 & 42850.0 & 640.4 & $<0.0001 * * *$ \\
\hline & Density (Den) & 2 & 1568.2 & 751 & 41282.0 & 784.1 & $<0.0001 * * *$ \\
\hline & DIV x Den & 1 & 19231.4 & 750 & 22051.0 & 19231.4 & $<0.0001 * * *$ \\
\hline \multirow[t]{8}{*}{ Pot } & NULL & & & 142 & 217.7 & & \\
\hline & Plant diversity (DIV) & 2 & 22.7 & 140 & 195.0 & 11.3 & $0.0 * * *$ \\
\hline & Cumulative drought (CD) & 5 & 5.9 & 135 & 189.2 & 1.2 & 0.32 \\
\hline & Density (Den) & 1 & 3.5 & 134 & 185.7 & 3.5 & 0.06 . \\
\hline & DIV x CD & 10 & 13.5 & 124 & 172.1 & 1.4 & 0.2 \\
\hline & DIV x Den & 2 & 1.2 & 122 & 170.9 & 0.6 & 0.55 \\
\hline & CD x Den & 5 & 2.1 & 117 & 168.8 & 0.4 & 0.82 \\
\hline & DIV x CD x Den & 10 & 14.0 & 107 & 154.7 & 1.4 & 0.17 \\
\hline
\end{tabular}

1 


\section{Table 2 (on next page)}

Analysis of deviance on effects fitted to seed germination of $A C$ and $B M$ and a 1:1 mixture of the two species in different the two laboratory trials

The analysis used a GLM with binomial error distribution and probit link function. 


\begin{tabular}{llcccccc}
\hline \multirow{1}{*}{ Trial } & Model & DF & Deviance & $\begin{array}{c}\text { Residual } \\
\text { DF }\end{array}$ & $\begin{array}{c}\text { Residual } \\
\text { deviance }\end{array}$ & F-value & P-value \\
\hline \multirow{2}{*}{ Laboratory 1 } & NULL & & & 71 & 237.8 & & $0.03 *$ \\
& Plant diversity (DIV) & 2 & 7.2 & 69 & 230.6 & 3.6 & 0.06. \\
& Spacing (SPA) & 1 & 3.7 & 68 & 226.9 & 3.7 & 0.11 \\
\hline Laboratory 2 & NUL x SPA & 2 & 4.4 & 55 & 96.1 & 2.2 & \\
& Plant diversity (DIV) & 2 & 180.2 & 429 & 2422.6 & 90.1 & $<0.0001 * * *$ \\
& Cumulative drought (CD) & 3 & 1016.6 & 424 & 1031.1 & 338.9 & $<0.0001 * * *$ \\
& Temperature (T) & 2 & 374.9 & 427 & 2047.7 & 187.4 & $<0.0001 * * *$ \\
& DIV x CD & 6 & 4.2 & 413 & 878.3 & 0.7 & 0.65 \\
& DIV x T & 4 & 148.0 & 419 & 882.5 & 37.0 & $<0.0001 * * *$ \\
& CD xT & 6 & 31.0 & 407 & 847.2 & 5.2 & $<0.0001 * * *$ \\
& DIV x CD x T & 12 & 14.4 & 395 & 832.8 & 1.2 & 0.27 \\
\hline
\end{tabular}

1 